\title{
Article \\ A Comprehensive Study of Pristine and Calcined f-MWCNTs Functionalized by Nitrogen-Containing Functional Groups
}

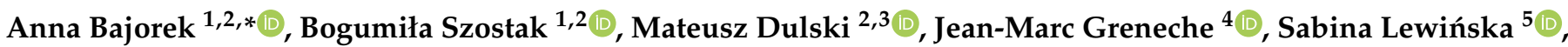 \\ Barbara Liszka $^{6}$, Mirosława Pawlyta ${ }^{7}$ (D) and Anna Ślawska-Waniewska ${ }^{5}$
}

1 A. Chełkowski Institute of Physics, University of Silesia in Katowice, 75 Pułku Piechoty 1A, 41-500 Chorzów, Poland; szostakbogumila@gmail.com

2 Silesian Center for Education and Interdisciplinary Research, University of Silesia in Katowice, 75 Pułku Piechoty 1A, 41-500 Chorzów, Poland; mateusz.dulski@us.edu.pl

3 Institute of Materials Science, University of Silesia in Katowice, 75 Pułku Piechoty 1A, 41-500 Chorzów, Poland

4 Institut des Molécules et Matériaux du Mans UMR CNRS 6283, Le Mans Université, Avenue Olivier Messiaen, CEDEX 9, 72085 Le Mans, France; jean-marc.greneche@univ-lemans.fr

5 Institute of Physics, Polish Academy of Sciences, Al. Lotników 32/46, 02-668 Warsaw, Poland; lewinska@ifpan.edu.pl (S.L.); slaws@ifpan.edu.pl (A.Ś.-W.)

6 Faculty of Natural Sciences, University of Silesia in Katowice, Będzińska 60, 41-200 Sosnowiec, Poland; barbara.liszka@us.edu.pl

7 Materials Research Laboratory, Institute of Engineering Materials and Biomaterials, Silesian University of Technology, Konarskiego 18A, 44-100 Gliwice, Poland; miroslawa.pawlyta@polsl.pl

* Correspondence: anna.bajorek@us.edu.pl

\section{check for}

updates

Citation: Bajorek, A.; Szostak, B.; Dulski, M.; Greneche, J.-M.; Lewińska, S.; Liszka, B.; Pawlyta, M.; ŚlawskaWaniewska, A. A Comprehensive Study of Pristine and Calcined f-MWCNTs Functionalized by Nitrogen-Containing Functional Groups. Materials 2022, 15, 977. https://doi.org/10.3390/ ma15030977

Academic Editor: Werner Blau

Received: 23 December 2021

Accepted: 25 January 2022

Published: 27 January 2022

Publisher's Note: MDPI stays neutral with regard to jurisdictional claims in published maps and institutional affiliations.

Copyright: (C) 2022 by the authors. Licensee MDPI, Basel, Switzerland. This article is an open access article distributed under the terms and conditions of the Creative Commons Attribution (CC BY) license (https:// creativecommons.org/licenses/by/ $4.0 /)$

\begin{abstract}
We present the study of pristine and calcined f-MWCNTs functionalized by nitrogencontaining functional groups. We focus on the structural and microstructural modification tuned by the previous annealing. However, our primary goal was to analyze the electronic structure and magnetic properties in relation to the structural properties using a multi-technique approach. The studies carried out by X-ray diffraction, XPS, and ${ }^{57}$ Fe Mössbauer spectrometry revealed the presence of $\gamma$-Fe nanoparticles, $\mathrm{Fe}_{3} \mathrm{C}$, and $\alpha-\mathrm{FeOOH}$ as catalyst residues. XPS analysis based on the deconvolution of core level lines confirmed the presence of various nitrogen-based functional groups due to the purification and functionalization process of the nanotubes. The annealing procedure leads to a structural modification mainly associated with removing surface impurities as purification residues. Magnetic studies confirmed a significant contribution of $\mathrm{Fe}_{3} \mathrm{C}$ as evidenced by a Curie temperature estimated at $T_{C}=452 \pm 15 \mathrm{~K}$. A slight change in magnetic properties upon annealing was revealed. The detailed studies performed on nanotubes are extremely important for the further synthesis of composite materials based on f-MWCNTs.
\end{abstract}

Keywords: carbon nanotubes; structural properties; magnetic properties; electronic structure

\section{Introduction}

Carbon nanotubes (CNTs) were intensively studied immediately after their discovery by Suimo Ijima in 1990 [1]. He demonstrated the presence of nanocylindrical forms of pure $\mathrm{sp}^{2}$ carbon having several micrometres long and several nanometers in diameter [1-3]. Thus, CNTs can be considered as a hexagonal array of carbon atoms wound in a hollow cylinder in two ways: single-walled nanotubes (SWCNTs) and multi-walled (MWCNTs) nanotubes [1]. These materials are characterized in particular by (i) outstanding mechanical and structural properties; (ii) good surface to area ratio; (iii) unique electrical conductivity; (iv) chemical and thermal stability, making them attractive components for nanohybrids [4-15]. Nevertheless, CNTs, usually in their pristine form, tend to aggregate by forming agglomerates combined with van der Waals interactions [16]. Because pristine CNTs are hydrophobic and chemically inert, their functionalization with various suitable 
organic groups leads to new activities on the CNT surface for nanoparticle grafting, which enhances their hydrophilicity and dispersibility in several solvents [17-26]. Understanding the impact of the functionalization type on the various properties of CNTs is one of the key factors for their potential future applications. Keeping in mind the development of nanotechnology, the electronic and magnetic properties of CNTs could be exploited, for example, in the design and synthesis of nanocomposite materials [4-15]. In general, MWCNTs are promising candidates for building blocks to build nanocomposites. However, it should be emphasized that in describing the properties of these materials, the iron-like species embedded in MWCNTs must be considered, as the Fe catalyst precursor formed in situ is the active centre for carbon filament formation [27-39]. Usually, $\alpha$-Fe, $\gamma$-Fe and $\mathrm{Fe}_{3} \mathrm{C}$ phases have been detected in Fe-filled CNT, but their relative content is strictly dependent on the synthesis procedure and post-treatment [27-39]. Baker et al. [27] demonstrated the detection of several iron carbides during the formation of carbon filaments. In contrast, based on X-ray diffraction analysis, Sacco et al. [28] revealed that the formation of $\mathrm{Fe}_{3} \mathrm{C}$ is responsible for the initial growth of carbon filaments and $\alpha$-Fe as a product of heating in a gas mixture containing carbon precursors. The presence of several iron carbides as intermediates in filament growth has also been proposed by Geus et al. [29,30]. However, the detailed description of the nature of the iron precursor in CNTs is still a challenging task, and the use of multi-technique characterization to solve this problem is highly demanded. Schaper et al. [31] reported in situ electron microscopy studies demonstrating the role of cementite as an intermediate in the catalytic formation of nanotubes by promoting the successive segregation of new well-ordered graphene layers on its surface.

A promising tool for analyzing iron species in MWCNTs is ${ }^{57} \mathrm{Fe}$ Mössbauer spectrometry, which allows the analysis of the different valence and spin states of Fe forms. So far, using this method, it has been shown that traces of Fe-based catalyst can be easily deposited inside MWCNTs during their synthesis and that iron aggregates can be reduced by almost $90 \%$ by the oxidation process [34,37-40]. However, the functionalization of carboxylated carbon nanotubes by fabricating CNT ammonium salt does not remove more Fe impurities but only changes the iron states. In pristine MWCNTs, the main component is $\mathrm{Fe}_{3} \mathrm{C}$, transformed into ferrihydrites during the oxidation process. In addition, treatment with $\mathrm{NH}_{3}$ leads to further oxidation of the cementite, where half of the $\mathrm{Fe}_{3} \mathrm{C}$ is transformed into hydrated superparamagnetic $\mathrm{Fe}_{2} \mathrm{O}_{3}$ particles. However, the relative content of $\alpha$-Fe in the iron grains embedded in the CNT samples remains relatively unchanged $[34,38-40]$. Prados et al. [36], based on Mössbauer analysis and hysteresis loops, claimed that the Fe catalyst precursors present in nanotubes consisted of a core of $\alpha$-Fe surrounded by layers of $\gamma$-Fe, $\mathrm{Fe}_{3} \mathrm{C}$, and carbon.

In view of the ongoing discussion on the form of $\mathrm{Fe}$ as a catalyst precursor in MWCNTs, in the following paper, we have focused on a comprehensive study of pristine and calcined f-MWCNTs functionalized with $\mathrm{COONH}_{4}$ groups. We present a detailed chemical and structural analysis of the Fe nanoparticles embedded in the nanotubes, combined with the analysis of the magnetic properties. We discussed the effect of calcination on the studied properties. The analysis we have performed will subsequently be effective in the ongoing synthesis of spinel ferrites nanoparticles/carbon nanotubes (SF-NPs/CNTs) nanocomposites targeting the synergic effect that could extend their potential applications, making them very attractive for further new nanomaterials development. The clarification of the nature of Fe-residuals in nanotubes is desirable due to their subsequent use in the synthesis of nanocomposites for theranostics materials, e.g., magnetic hyperthermia or as contrast agents for magnetic resonance.

\section{Materials and Methods}

\subsection{Sample}

The functionalized multi-walled carbon nanotubes (f-MWCNTs) with a 99\% purity were purchased commercially (Smart Nanotechnologies, Cracow, Poland). The product was synthesized using a Fe-based catalyst by catalytic chemical vapour deposition (CCVD). 
As indicated by the producer, the pristine MWCNTs were purified in a mixture of nitric acid $\left(\mathrm{HNO}_{3}\right)$ and sulphuric acid $\left(\mathrm{H}_{2} \mathrm{SO}_{4}\right)$. Then, the purified nanotubes were functionalized with a carboxyl-ammonium group to obtain the final $\mathrm{MWCNTs}-\mathrm{COONH}_{4}$ material subsequently denoted by us as f-MWCNTs. The detailed synthesis conditions are trade secrets. The water-soluble multiwall carbon nanotubes (MWCNTs-COONH4) exhibit an average outer diameter of about 20-25 nm (based on our TEM observations) and length from 1 to $25 \mu \mathrm{m}$ (declared by the producer).

The carbon nanotubes were studied in pristine and calcined form. The calcination was carried out at $100{ }^{\circ} \mathrm{C}, 200^{\circ} \mathrm{C}$, and $300{ }^{\circ} \mathrm{C}$ under argon protection in a flow of $20 \mathrm{~mL} / \mathrm{min}$. The process was conducted in a horizontal quartz tube being a part of the oven (Czylok, Jastrzebie Zdroj, Poland) with controller temperature. The rate of temperature was $5{ }^{\circ} \mathrm{C} / \mathrm{min}$. The calcinated sample was stored at the final temperature for $1 \mathrm{~h}$. The applied argon was with purity grade (99.999\%, Linde, Cracow, Poland). The annealing temperature was chosen, taking into account future applications of $\mathrm{f}-\mathrm{MWCNTs}$ as a component in spinel ferrite (SF) nanocomposites [26] to maintain the magnetic structure of SF nanoparticles. It is worth noting that initially, Fe was incorporated into MWCNTs during the synthesis process as a catalyst.

\subsection{Methods}

The crystal structure of f-MWCNTs was examined using X-ray Powder Diffraction (XRD, Malvern Instruments, Malvern, UK) using the Empyrean PANalytical diffractometer. The monochromatized $\mathrm{Cu}$ X-ray source of $\mathrm{K} \alpha_{1}=1.54056 \AA$ and the Bragg-Brentano geometry $\theta-2 \theta$ were used. All detected crystalline phases were identified based on the PDF-4 database.

For Transmission Electron Microscopy (TEM) studies, specimens were prepared by dispersing a small quantity of samples in ethanol using the ultrasonic washer (InterSonic, Olsztyn, Poland). Then, a droplet of such suspension was placed on a microscope copper grid covered with carbon. TEM studies were performed on an aberration-corrected FEI Titan electron microscope (S/TEM Titan 80-300 from FEI Co., Eindhoven, The Netherlands) operating at $300 \mathrm{kV}$.

All X-ray Photoemission Spectroscopy (XPS, Physical Electronics Inc., Eden Prairie, $\mathrm{MN}, \mathrm{USA}$ ) results were obtained at room temperature by using an aluminium monochromatized X-ray source of $\mathrm{K} \alpha=1486.6 \mathrm{eV}$ photon energy as part of the PHI 5700/660. spectrometer placed in the U.H.V. cluster. The sample was attached to the sample holder by double-coated conductive carbon tabs (PELCO Tabs ${ }^{\mathrm{TM}}$, Ted Pella Inc., Redding, CA, USA) and subsequently stored in the parking chamber under an ultra-high vacuum of $10^{-9}$ Torr for about 7 days. After storage time, each studied sample was transferred into the main chamber and directly analyzed. Then, the same specimen at the same position was sputtered by $\mathrm{Ar}^{+}$ion beam for $30 \mathrm{~min}$, and afterwards, was subsequently measured. This ion cleaning procedure was chosen based on previous research [26]. Before analysis, each measured XPS spectra was calibrated using the $\mathrm{C} 1$ s peak $(\mathrm{BE}=284.8 \mathrm{eV})$ as the carbon peak usually originates from the carbon adsorbed on the surface and is used in XPS analysis as a reference for charge correction. All measured spectra were processed using MultiPak 9.6 software (Physical Electronics Inc., Eden Prairie, MN, USA). The core level lines were measured in the multiplex mode with pass energy $23.5 \mathrm{eV}$ and resolution $0.1 \mathrm{eV}$. The time of measurement of each line was adjusted based on the peak intensity estimated from survey spectra. The deconvolution of the core level lines was performed by applying the Shirley-type background and the generally Gaussian-Lorentzian shape of lines. All details obtained after deconvolutions for each core level peak are provided in Supplementary Materials as separate tables. The fitting accuracy is reasonable, as expected.

The magnetic properties of the pristine nanotubes were determined using a widerange Superconducting Quantum Interference Device (SQUID) magnetometer MPMS XL7 Quantum Design (MPMS, Quantum Design Inc., San Diego, CA, USA), while a commercial Physical Property Measurement System (PPMS) (Quantum Design Inc., San Diego, CA, 
USA) with Vibrating Sample Magnetometer (VSM) (Quantum Design Inc., San Diego, CA, USA) and VSM Oven options were used to study the magnetic behaviour of the annealed specimens. The thermal dependence of the DC magnetization was collected in the zerofield-cooled (ZFC) and field-cooled (FC) modes at the external field of 100 Oe and 1000 Oe, in the temperature range from 2 to $400 \mathrm{~K}$, while the isothermal magnetic curves $\mathrm{M}(\mathrm{H})$ were recorded at $2 \mathrm{~K}, 100 \mathrm{~K}$, and $300 \mathrm{~K}$.

The Mössbauer spectra were recorded at 300 and $77 \mathrm{~K}$ using a standard transmission geometry equipped with a conventional constant acceleration spectrometer (Wissenschaftliche Elektronik WissEL GMBH, Munchen, Germany) and a ${ }^{57} \mathrm{Fe}$ source diffused into an Rh matrix. A spectrum calibration was made with pure $\alpha$-Fe powder, and the isomer shift values are quoted to $\alpha$-Fe at $300 \mathrm{~K}$.

\section{Results and Discussion}

\section{1. $X R D$}

The XRD patterns for all the f-MWCNTs specimens studied are shown in Figure 1. The XRD pattern for each studied nanotubes is complex is dominated by the presence of indexed peaks such as (002), (100), (004), and (110) at $2 \theta=26.34^{\circ}, 43.35^{\circ}, 56.86^{\circ}, 78.48^{\circ}$, respectively, according to ICDD reference 00-058-1638. Nevertheless, impurities as postfunctionalization products are evidenced and marked by additional peaks according to the ICDD database (see Figure 1). One can notice the presence of ammonium nitrate $\mathrm{NH}_{4} \mathrm{NO}_{3}$ (ICDD 00-047-0864), ammonium sulfate $\left(\mathrm{NH}_{4}\right)_{2} \mathrm{~S}_{2} \mathrm{O}_{6}$ (ICDD 00-015-0241), and sulfuric acid $\mathrm{H}_{2} \mathrm{SO}_{4}$ (ICDD 04-014-6906). As can be seen, most of the organic impurities observed in the as-received nanotubes are removed after the calcination process. The analysis of the XRD pattern of the nanotubes is not trivial, mainly because we cannot exclude the presence of turbostratic carbon, visible as asymmetric peaks considered due to disordered graphene layers [41,42]. Indeed, TEM analysis revealed defects and damaged walls (see Figure 2). Furthermore, it has been shown that $\mathrm{NH}_{3}$ treatment can promote the formation of the turbostratic structure [43]. In addition, published results point out the presence of iron carbides (mainly) cementite during the synthesis of CNTs [35]. Other Fe-based contributions as catalyst residues are also discussed and studied [27-40]. However, the exact identification of each crystal phase of iron form and their content by XRD measurements is complicated due to their crystalline structures similarities.

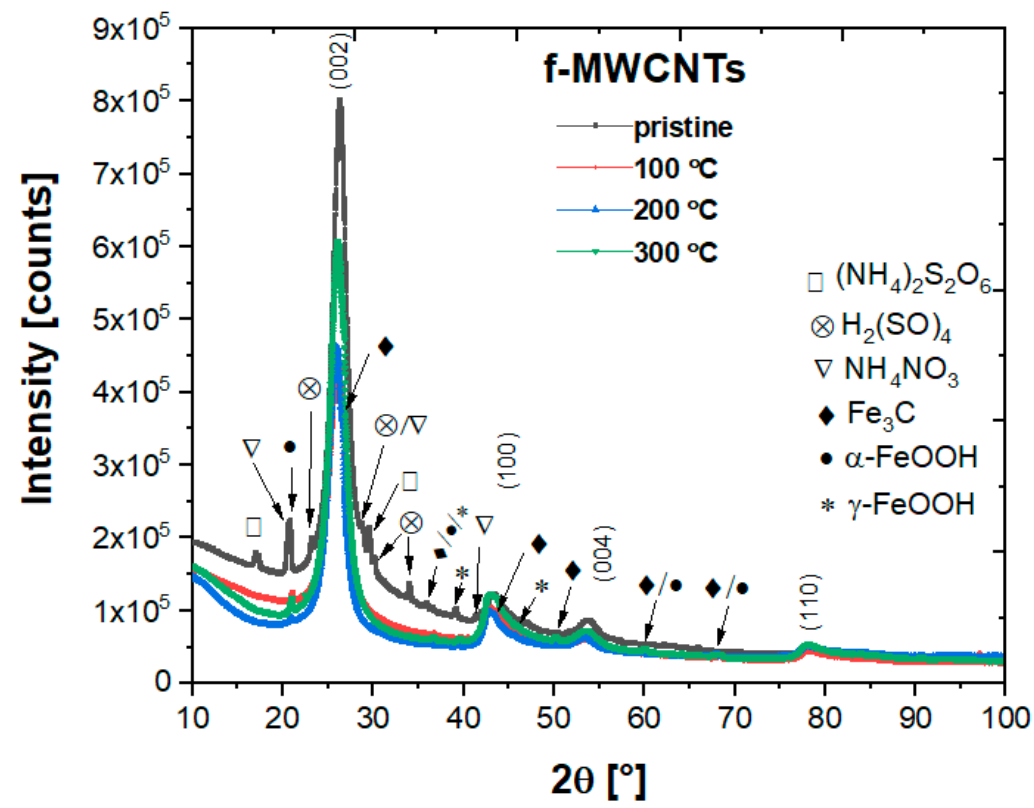

Figure 1. XRD diffractograms for pristine and calcined f-MWCNTs. 
Nevertheless, some characteristic XRD peaks are observed for both pristine and calcined nanotubes. It seems that the dominant Fe component is cementite (ICDD 00-0030400), mainly noticeable as a bump in the nanotube peaks around $\theta=26.5^{\circ}$ and $43.6^{\circ}$. Some of the other $\mathrm{Fe}_{3} \mathrm{C}$ peaks are probably partially overlapped with those of goethite $\alpha$-FeOOH (ICDD 00-001-0401) and lepidocrocite $\gamma$-FeOOH (ICDD 00-003-0079). In addition, the $\gamma$-Fe phase, which gives the most intensive peaks around $43.5^{\circ}$ (111) and 50.5 (200) (COD crystal database card 9008469), can be overlapped with other Fe-based structures, especially that $\gamma$-Fe was detected in Mössbauer spectrometry. Thus, the precise analysis of all Fe-based structures from XRD data at this research stage is not possible the more so because of the influence of the dominated turbostratic carbon, which causes line broadening. However, the presence of all in nanotubes cannot be neglected.

\subsection{TEM Microstructure}

A representative TEM image of the f-MWCNTs is shown in Figure 2. One may notice that the bunch of functionalized carbon nanotubes is very tangled (see Figure $2 \mathrm{a}$ ). The outer walls show many defects and are covered by amorphous layers, probably from purification products. In addition, the presence of embedded particles filling the inner cavity of the nanotube and varying in size is evident (see Figure $2 b$ ). Thus, these nanoparticles have an average size of 11-22 $\mathrm{nm}$ and can be recognized as post-synthesis catalyst residues.
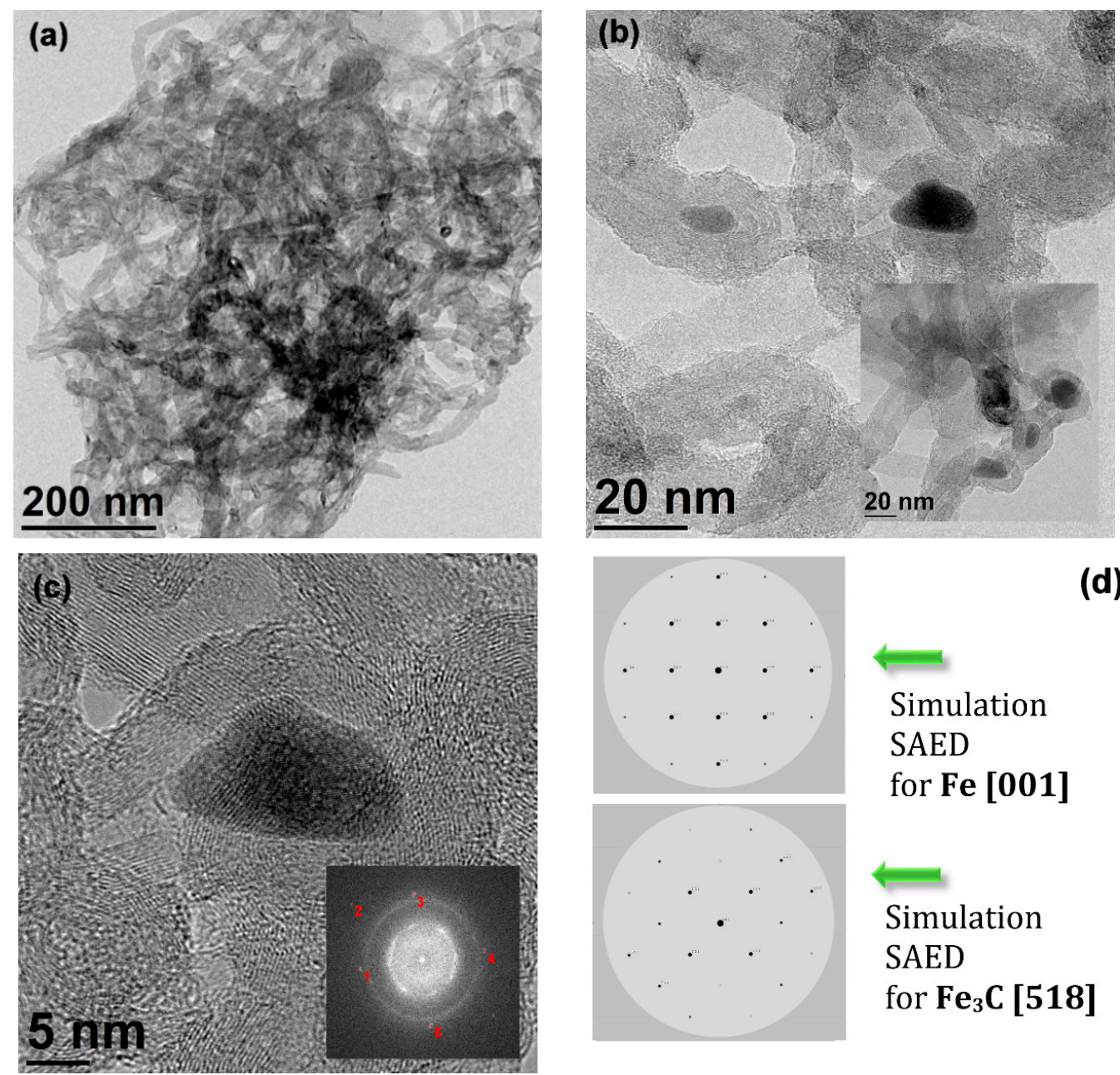

(d)

\section{Simulation \\ SAED for $\mathbf{F e}$ [001]}

Simulation
SAED
for $\mathbf{F e}_{3} \mathbf{C}$ [518]

Figure 2. TEM image for pristine f-MWCNTs (a) entangled nanotubes; (b) nanotubes with visible Fe-based catalyst residues; (c) Fe-based nanoparticle with FFT analysis placed as insert; (d) selection area electron diffraction (SAED) pattern simulation of Fe [001] and Fe3C [518] phases. 
The inset in Figure 2c shows the diffractogram taken on the particle displayed in the image. By analyzing the FFT, we can determine the interplanar spacing, and with welldefined graphite spacings, we can use the standard to identify Bragg reflections. Thus, we can deduce that the observed diffraction can be recognized as Fe $(\mathrm{Fm}-3 \mathrm{~m})$ in the direction of [001] or $\mathrm{Fe}_{3} \mathrm{C}$ diffraction in the direction of [518]. The latter corresponds better to the visible diffraction spots. Thus, for example, reflex numbers 1 and 3 observed with an interplanar spacing d of $1.82 \AA$ can be recognized as Fe(200) (tabular value-1.71 $⿱$ ) or $\mathrm{Fe}_{3} \mathrm{C}(13-1)$ (tabular value-1.87 $\AA$ ), which is a better match to $\mathrm{Fe}_{3} \mathrm{C}$. Thus, the two diffractions are similar, the angles are the same, and the spacings are very close, and it is not easy to decide which structure is visible in the embedded particles, which can be well demonstrated by the simulated SAED for Fe [001] and $\mathrm{Fe}_{3} \mathrm{C}$ [518] (see Figure 2d). Probably, we have a co-existing fraction of $\mathrm{Fe}_{3} \mathrm{C}, \mathrm{Fe}$, and possibly even iron oxides [32,44-46]. The applied calcination procedure does not drastically change the microstructure of the f-MWCNTs. It is worth adding that the cementite structure is composed of hexagonal close-packed layers of Fe atoms at two different sites with slightly different magnetic moments while carbon atoms occupy the interstitial sites.

\subsection{Raman Spectroscopy}

The Raman spectra of the pristine and heat-treated carbon nanotubes are summarized in Figure 3, while the Raman band positions and the intensity ratio are presented in Table 1. It is interesting to note that the spectrum of pristine CNTs displays D and G bands located at around 1360-1590 $\mathrm{cm}^{-1}$, which are associated, respectively, with defective and disordered graphitic layers on the surface wall $[45,47,48]$ as well as with in-plane vibrations of the graphite sheet [48]. In this context, the D band is generally attributable to disordered amorphous carbon but not the defects inside tube walls [49], while the $G$ band to the $(C=C)$ stretching vibration within the carbon ring. According to the literature, the $\mathrm{D}$ band is generally assigned to the A1g symmetry mode [47], while the G band corresponds to the E2g modes [50,51]. The strong D and G modes indicate a defective structure of the studied carbon nanotubes but without significant sidewall damage. Pristine carbon nanotubes are also loaded with tube surface defects due to a clearly visible $\mathrm{D}^{\prime}$ band around $1620 \mathrm{~cm}^{-1}$ [52].

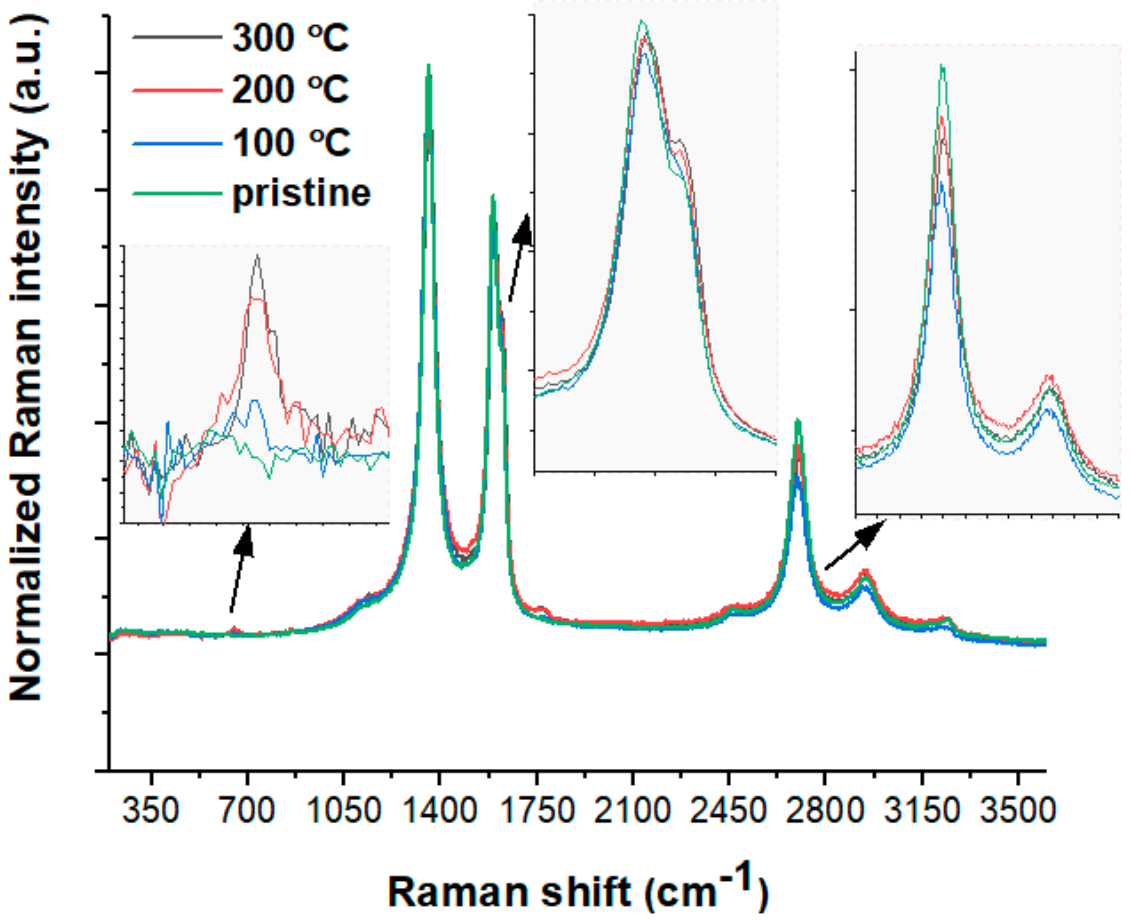

Figure 3. Raman spectra of pristine and calcined f-MWCNTs presented in the $200-3600 \mathrm{~cm}^{-1}$ range. 
The Raman spectra of the studied CNTs also revealed the $\mathrm{D}^{*}$ band at about $2690 \mathrm{~cm}^{-1}$, which is the second harmonic of the D band (see Table 1) [47,53]. According to the literature, the intensity of the $D^{*}$ band corresponds to the extent of impurities in the sample [49] or results from the mass fraction, i.e., the decrease in $\mathrm{D}^{*}$ intensity translates into a decrease in the CNT mass [53]. A very similar arrangement of Raman bands was found for the heat-treated samples with only slight differences in intensity and band positions (see Table 1).

Furthermore, two interesting observations were made when comparing the heattreated samples with the pristine material. First, a tiny Raman band around $700 \mathrm{~cm}^{-1}$ appeared on the CNTs sintered at $200{ }^{\circ} \mathrm{C}$ and $300{ }^{\circ} \mathrm{C}$, suggesting a surface evolution of the carbon nanotubes or, alternatively, point to the precipitation of some impurities or metals. Secondly, the decrease in the $\mathrm{D}^{*}$ value as a function of the annealing temperature of the nanotubes may suggest a decrease in the CNT mass fraction (Table 1). The data mentioned before can be used to probe the quality of carbon materials. Here, the ratio between the intensities of the $\mathrm{D}$ and $\mathrm{G}$ bands or $\mathrm{D}$ and $\mathrm{D}^{*}$ is generally useful for the characterization of carbon materials [54]. The changes in the $\mathrm{I}_{\mathrm{D}} / \mathrm{I}_{\mathrm{G}}$ and $\mathrm{I}_{\mathrm{D}} / \mathrm{I}_{\mathrm{D}}$ * ratios for each sample are given in Table 1 . Generally, the low value of $\mathrm{I}_{\mathrm{D}} / \mathrm{I}_{\mathrm{G}} \approx 0.23$ suggests a good quality of the carbon material. In the case of the pristine nanotube, the $\mathrm{I}_{\mathrm{D}} / \mathrm{I}_{\mathrm{G}}$ ratio is higher than 1.50 , indicating a higher amount of amorphous carbon. What is more interesting is that the $\mathrm{I}_{\mathrm{D}} / \mathrm{I}_{\mathrm{G}}$ values for the heat-treated samples are generally close to each other but are much higher than the value for the pristine material. Such behaviour could suggest the local increase in disordered amorphous carbon. The Raman study also allows the purity of the carbon materials to be checked by calculating the $\mathrm{I}_{\mathrm{D}} / \mathrm{I}_{\mathrm{D}}$ * ratios. The higher the $\mathrm{I}_{\mathrm{D}} / \mathrm{I}_{\mathrm{D}}$ * value, the purer the material studied. Our studies showed very high $\mathrm{I}_{\mathrm{D}} / \mathrm{I}_{\mathrm{D}}$ * values for all samples, suggesting relatively low carbon impurities, such as aliphatic moieties or methyl groups.

Table 1. Gaussian and Lorentzian fitting results of Raman spectra taking into account bands D, G, D', and $\mathrm{D}^{*}$, the intensity ratio of $\mathrm{I}_{\mathrm{D}} / \mathrm{I}_{\mathrm{G}}, \mathrm{I}_{\mathrm{D}} / \mathrm{I}_{\mathrm{D}}{ }^{*}$, and FWHM of pristine and calcinated carbon nanotubes.

\begin{tabular}{|c|c|c|c|c|c|c|}
\hline f-MWCNTs & $\begin{array}{c}\text { D } \\
\text { Band Position } \\
\left(\mathrm{cm}^{-1}\right)\end{array}$ & $\begin{array}{c}\mathrm{G} \\
\text { Band Position } \\
\left(\mathrm{cm}^{-1}\right)\end{array}$ & $\begin{array}{c}\mathrm{D}^{\prime} \\
\text { Band Position } \\
\left(\mathrm{cm}^{-1}\right)\end{array}$ & $\begin{array}{c}D^{*} \\
\text { Band Position } \\
\left(\mathrm{cm}^{-1}\right)\end{array}$ & $\mathbf{I}_{\mathrm{D}} / \mathbf{I}_{\mathrm{G}}$ & $\mathbf{I}_{\mathbf{D}} / \mathbf{I}_{\mathbf{D}}{ }^{*}$ \\
\hline pristine & 1357.4 & 1587.1 & 1619.6 & 2693.1 & 1.89 & 2.45 \\
\hline $100^{\circ} \mathrm{C}$ & 1357.8 & 1587.6 & 1619.5 & 2691.8 & 2.14 & 3.51 \\
\hline $200^{\circ} \mathrm{C}$ & 1358.3 & 1587.5 & 1619.6 & 2692.8 & 2.12 & 3.26 \\
\hline $300^{\circ} \mathrm{C}$ & 1359.1 & 1588.6 & 1620.1 & 2694.9 & 1.98 & 2.89 \\
\hline
\end{tabular}

\subsection{X-ray Photoemission Spectroscopy (XPS)}

The electronic structure of various carbon nanotubes can be effectively studied by XPS measurements [17-21,55-59]. However, it is important to remember first that the sensitivity of XPS is limited to the surface with a depth of about $10 \mathrm{~nm}$ for the monochromatized Al source. The changes in the valence band (VB) spectra as a function of sample treatment are illustrated in Figure 4. There is no significant difference in VB between all samples, meaning that the calcination process did not affect the high degree of crystallinity of the CNTs wall structure. However, after annealing at $300{ }^{\circ} \mathrm{C}$, a slight increase in the states around the Fermi level $\left(E_{F}\right)$ can be noted, which can probably be associated with the influence of the Fe-based magnetic components modified over heat treatment. Nevertheless, such states with a noticeable bump around $4.1 \mathrm{eV}$ may also be evidence of $\mathrm{sp}^{2}$ hybridized nitrogen as photoelectrons emitted from nitrogen lone pair states, as already demonstrated by Ruelle et al. [17]. 


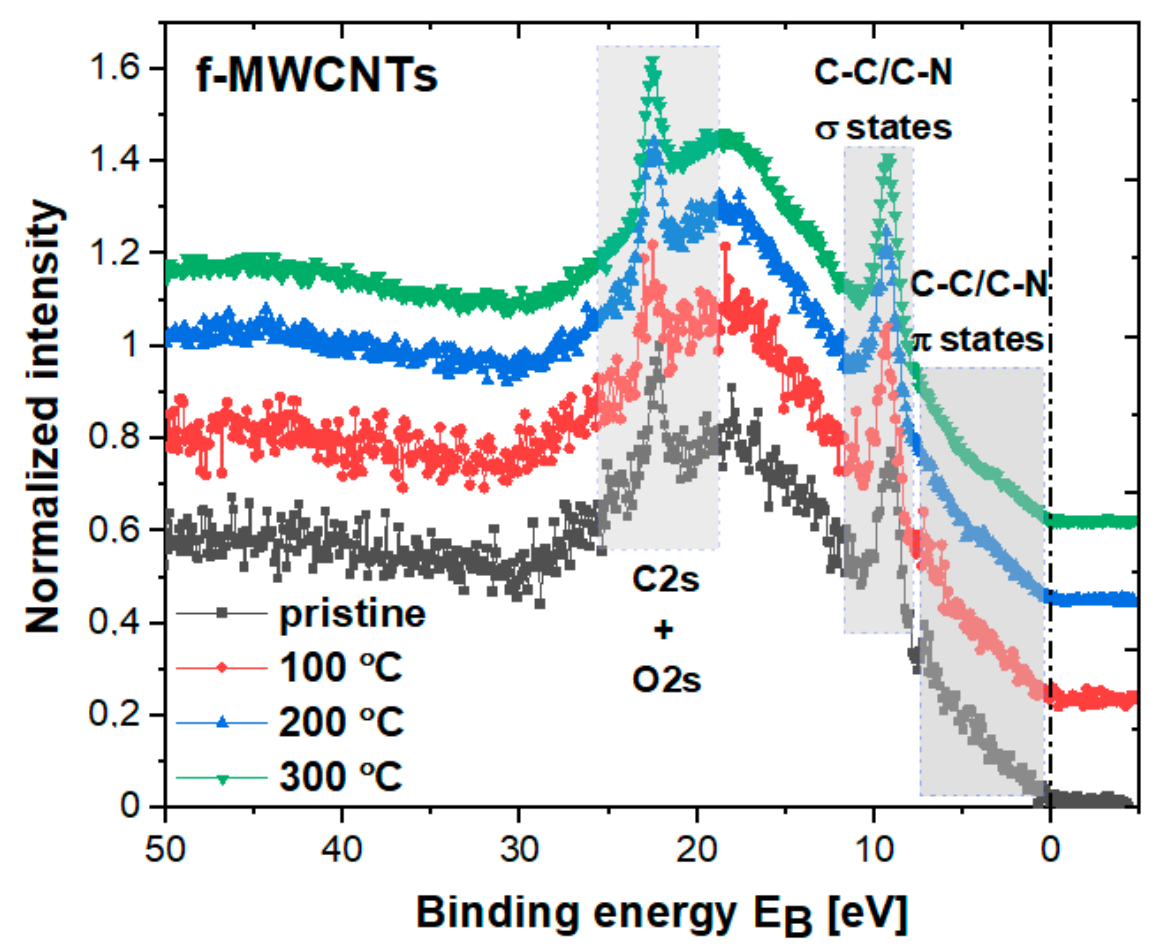

Figure 4. The comparison between valence bands in pristine and calcined f-MWCNTs samples.

By analyzing the VB, one can notice a distinguishable peak in the binding energy range of about $\mathrm{BE} \approx 7.4-11 \mathrm{eV}$ with the maximum at about $\mathrm{BE} \approx 9.3 \mathrm{eV}$ that be assigned to overlapped $\mathrm{C}-\mathrm{C} / \mathrm{C}-\mathrm{N} 2 \mathrm{p}-\sigma$ states, probably also enhanced by $\mathrm{C}-\mathrm{O}$ states [60]. Similarly, between $\mathrm{E}_{\mathrm{F}}$ and $7 \mathrm{eV}$, the relatively flat states can be attributed to $\mathrm{C}-\mathrm{C} / \mathrm{C}-\mathrm{N} 2 \mathrm{p}-\pi$ states. The next prominent peak between $20 \mathrm{eV}$ and $24 \mathrm{eV}$ may originate from overlapped $\mathrm{C} 2 \mathrm{~s}$ and $\mathrm{O} 2 \mathrm{~s}$ states. The valence band of carbon nanotubes has been successfully described by, e.g., Ruelle et al. [17] and Nesov et al. [59]. The band structure pattern determined is similar to that observed by us, but the sharp and prominent peaks in the VB noted in our studies and described as $\mathrm{C}-\mathrm{C} / \mathrm{C}-\mathrm{N} 2 \mathrm{p}-\sigma$ states and $\mathrm{C} / \mathrm{O} 2 \mathrm{~s}$ states are a rather new phenomenon. So far, these states have been described as broad bands. Here, the first peak can probably be associated with various $\mathrm{N}$-based groups, e.g., graphitic nitrogen, where a nitrogen atom is substituting a carbon atom and is incorporated into the graphene layer. It appears that the VB configuration is strictly associated with the way of CNTs synthesis and further functionalization.

The C1s core level lines (see Figure 5) are asymmetric and can be deconvoluted into five components as for carbon nanotubes [17-21,55-59] (see Table S1 in Supplementary Materials). The first one, around $284.8 \mathrm{eV}$, which is dominant, can be assigned to the $\mathrm{C}=\mathrm{C}$ $\mathrm{sp}^{2}$ carbon bonds, which are rather overlapped with the sp3 $\mathrm{C}-\mathrm{C}$ bonds. It is interesting to note that $\mathrm{Fe}-\mathrm{C}$ states from catalyst residues can also overlap this peak, but their content is relatively low. These states are usually visible as small peaks around $283.5 \mathrm{eV}$, indicating a rather strong interaction between $\mathrm{Fe} 3 \mathrm{C}$ and the surface of the graphene layer [61,62]. The next peak, around $285.9 \mathrm{eV}$, represents the $\mathrm{C}-\mathrm{O}$ and $\mathrm{C}=\mathrm{N}$ state, while the one around $287 \mathrm{eV}$ may represent $\mathrm{C}=\mathrm{O}$ overlapped with sp3 $\mathrm{C}-\mathrm{N}$. The following broad line, above $288.6 \mathrm{eV}$, can be attributed to the carboxyl $\mathrm{O}-\mathrm{C}=\mathrm{O}$ component. The last broad line with the lowest intensity near $290 \mathrm{eV}$ can be identified as a satellite $\pi-\pi-^{*}$ shake-up from the sp ${ }^{2}$ hybridized carbon. 

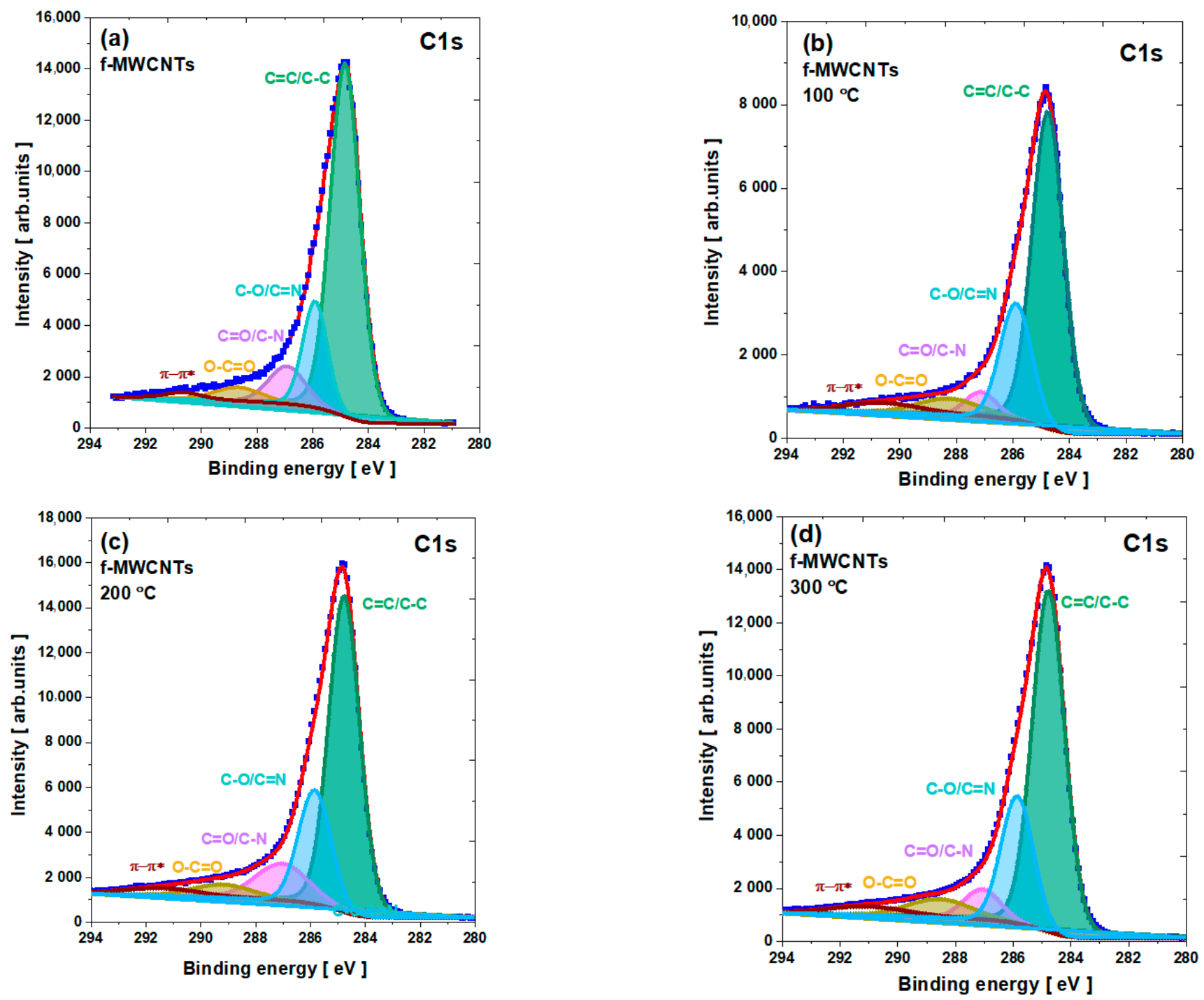

Figure 5. The $\mathrm{C} 1$ s core level line for f-MWCNTs: (a) pristine; calcined at (b) $100{ }^{\circ} \mathrm{C}$; (c) $200{ }^{\circ} \mathrm{C}$; and (d) $300{ }^{\circ} \mathrm{C}$.

The N1s spectra of pristine and calcined nanotubes reveal several contributions related to N-based functionalities (see Figure 6), namely N1, N2, N3, and N4 (see Table S2 in Supplementary Materials). The N1 peaking around $399 \mathrm{eV}$ can be identified as pyridine and nitryl groups; $\mathrm{N} 2$ around $400 \mathrm{eV}$ to amide, amine, lactam, and pyrrole; the N3 observed around $402 \mathrm{eV}$ to quaternary nitrogen atoms bonded to three $\mathrm{C}$ atoms in the bulk of the graphene layers; the broad N4 peak around $406 \mathrm{eV}$ to pyridine-N-oxide overlapped with probably dominated adsorbed $\mathrm{N}^{2}[4,18,21,26]$. The relative percentage of the different $\mathrm{N}$-species was determined for each sample based on the deconvoluted spectra. For the pristine f-MWCNTs, we observe all four nitrogen-based lines, whereas, for the calcined specimens, only three components are visible with different relative percentage contributions. Moreover, the N2 component dominates for both pristine and calcined nanotubes. This contribution is probably enhanced with $\mathrm{Fe}-\mathrm{N}$ states due to the presence of $\mathrm{Fe} / \mathrm{Fe}_{3} \mathrm{C}$ catalyst residues [62]. N3 is reduced after calcination to about 9 at. \% for the sample calcined at $300{ }^{\circ} \mathrm{C}$. The modification of the nitrogen-based group during the calcination process has already been observed, for example, by Kundu et al. [29], who studied CNTs heat-treated under $\mathrm{NH}_{3}$ at different temperatures. As in the case of our samples, he determined the domination of the $\mathrm{N} 2$ states for the sample annealed at $200{ }^{\circ} \mathrm{C}$. 

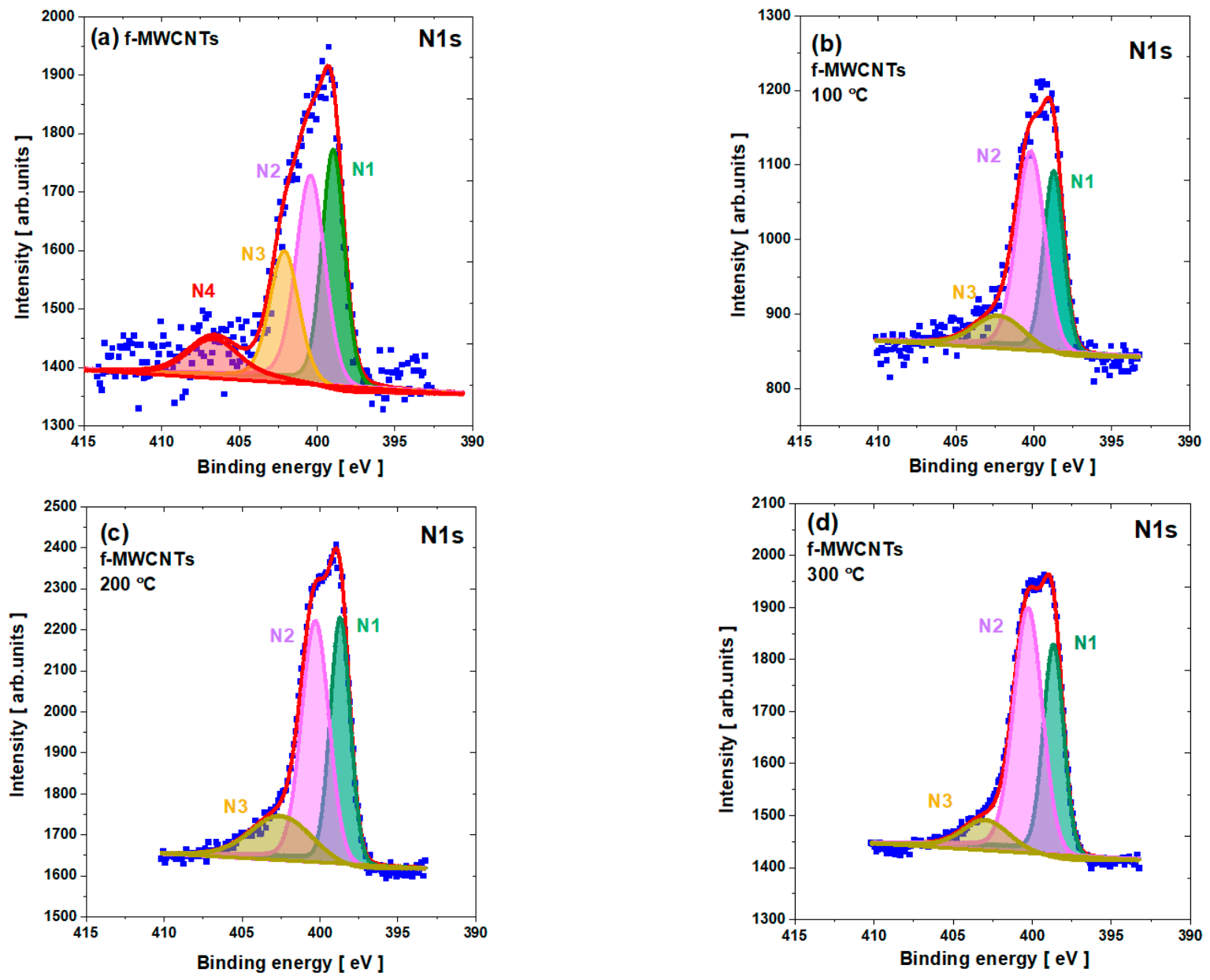

Figure 6. The N1s core level line for f-MWCNTs: (a) pristine; (b) calcined at $100{ }^{\circ} \mathrm{C}$; (c) calcined at $200{ }^{\circ} \mathrm{C}$; and (d) calcined at $300{ }^{\circ} \mathrm{C}$.

The O1s line is complex for all the nanotubes studied and can be attributed to three species (see Figure 7) (see Table S3 in Supplementary Materials). The complexity of the O1s line can be derived from various components related to $\mathrm{C}=\mathrm{O}(\mathrm{BE} \approx 531.6 \mathrm{eV}), \mathrm{C}-\mathrm{O} / \mathrm{C}-\mathrm{OH}$ $(\mathrm{BE} \approx 533.2 \mathrm{eV})$, and the peak at about $536 \mathrm{eV}$. The first peak dominates pristine nanotubes, while the second is dominant for calcined nanotubes. Moreover, the last peak for the pristine f-MWCNTs can probably be caused by physisorbed water as an effect of functionalization in the wet environment, while for the calcined samples, this peak becomes very broad, probably due to the overlap with the $\mathrm{Si}-\mathrm{O}$ states as an effect of the nanotube annealing on the quartz boat. It should also be emphasized that the second peak can be enhanced by the $\mathrm{N}-\mathrm{O}$ bonding sites generally noticeable around $534 \mathrm{eV}$.

The analysis of the S2p spectra indicates a small contribution of the sulfur-based components (see Figure 8) as residues from the purification of the nanotubes (see Table S4 in Supplementary Materials). Nevertheless, the sulfur line exhibits two prominent peaks that can be recognized as $\mathrm{C}-\mathrm{S}-\mathrm{C}$ and $\mathrm{S}-\mathrm{O}$ states. The first is visible as two distinct peaks $\mathrm{S} 2 \mathrm{p}_{3 / 2}$ and $\mathrm{S} 2 \mathrm{p}_{1 / 2}$, around $\mathrm{BE} \approx 163.7 \mathrm{eV}$ and $\mathrm{BE} \approx 164.9 \mathrm{eV}$, respectively, and probably enhanced by the Fe-S states [62]. The second states are also revealed by two peaks, $\mathrm{S}_{2} \mathrm{p}_{3 / 2}$ and $\mathrm{S} 2 \mathrm{p}_{1 / 2}$, around $\mathrm{BE} \approx 168.5 \mathrm{eV}$ and $\mathrm{BE} \approx 169.7 \mathrm{eV}$. In the case of pristine nanotubes, both sulfur states are noted. However, as can be observed, the calcination procedure slightly reduces the $\mathrm{S}-\mathrm{O}$ states until they disappear entirely after annealing at $300{ }^{\circ} \mathrm{C}$. Concomitantly, sulfur-carbon states as a covalent bond are visible for all the studied samples. 

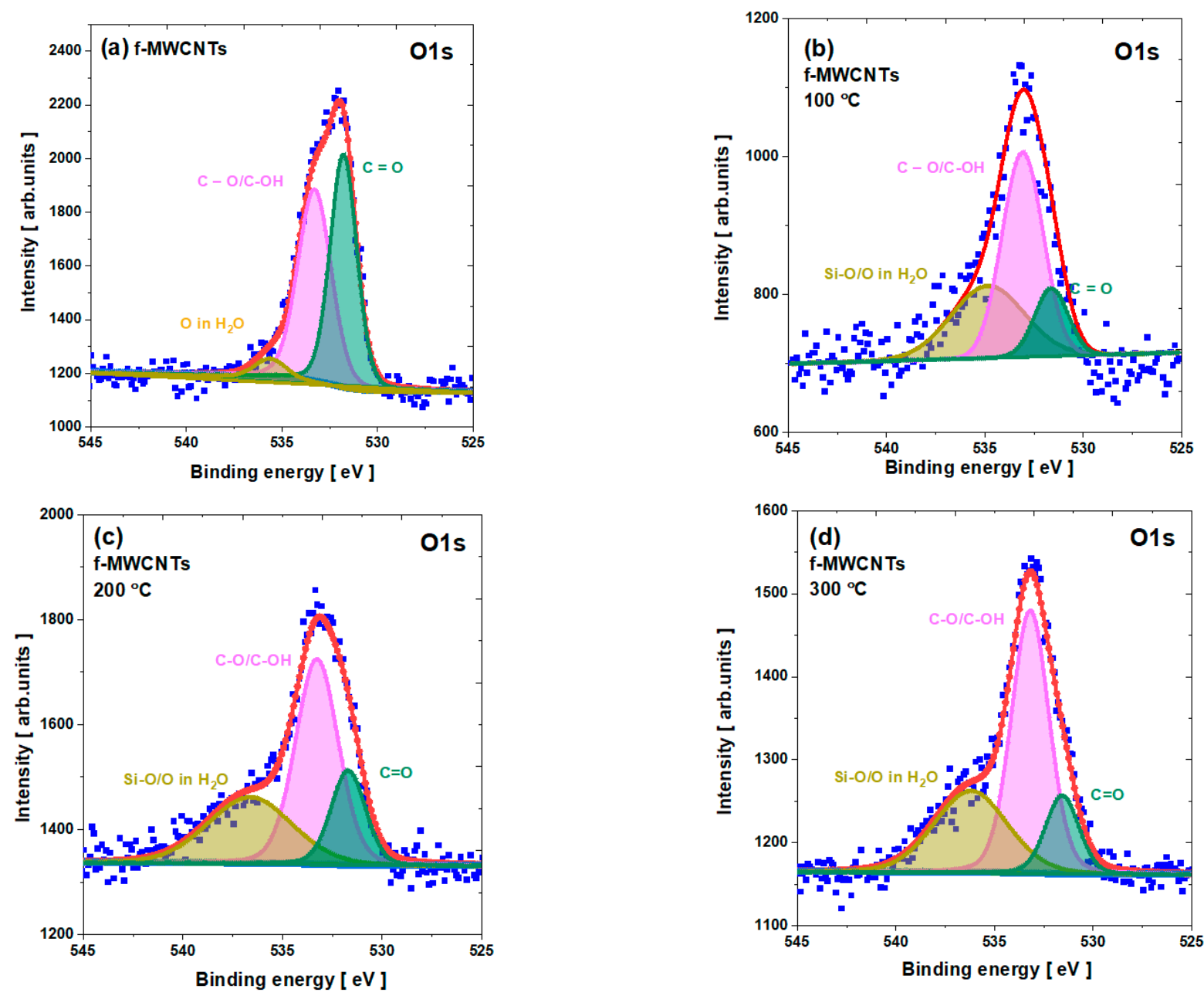

Figure 7. The O1s core level line for f-MWCNTs: (a) pristine; (b) calcined at $100{ }^{\circ} \mathrm{C} ;(\mathbf{c})$ calcined at $20{ }^{\circ} \mathrm{C}$; and (d) calcined at $300^{\circ} \mathrm{C}$.
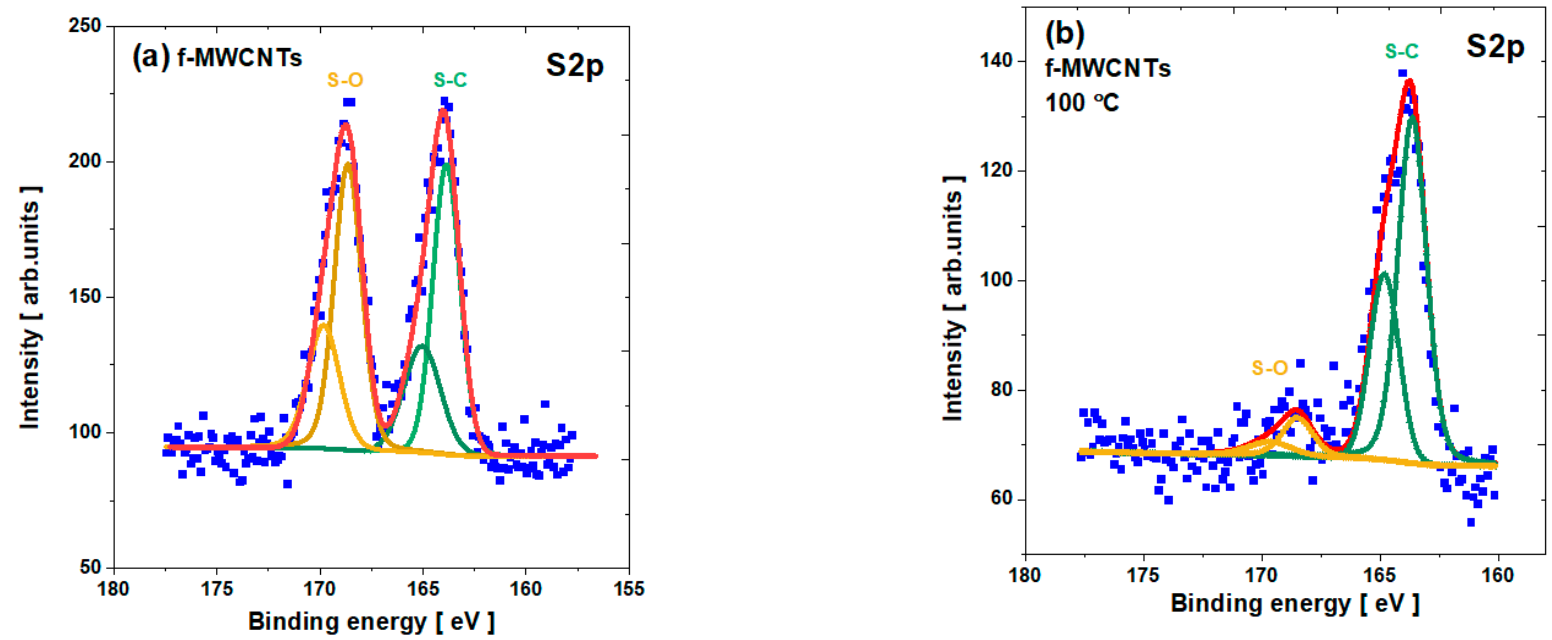

Figure 8. Cont. 

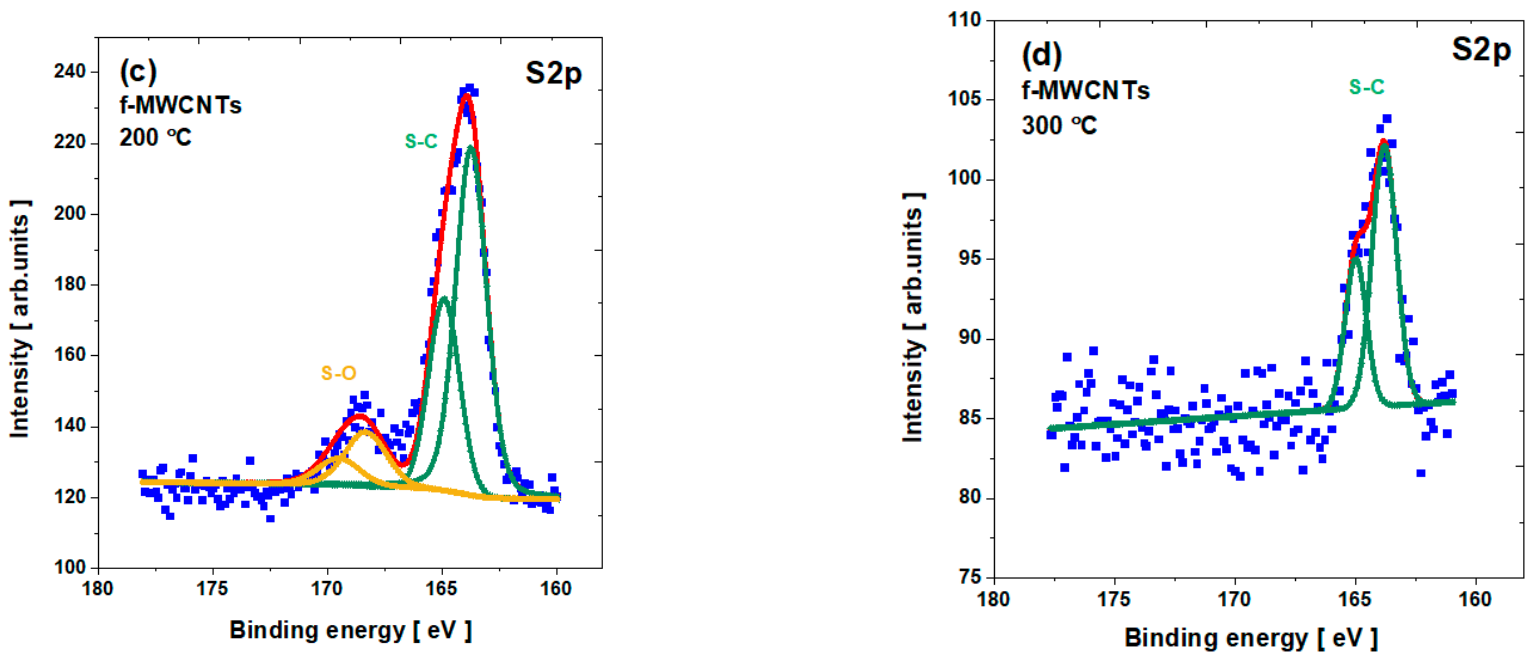

Figure 8. The S2p core level line for f-MWCNTs: (a) pristine; (b) calcined at $100{ }^{\circ} \mathrm{C}$; (c) calcined at $200{ }^{\circ} \mathrm{C}$; and $(\mathbf{d})$ calcined at $300{ }^{\circ} \mathrm{C}$.

The example of the Fe2p line measured for $\mathrm{f}-\mathrm{MWCNT}$ calcined at $200{ }^{\circ} \mathrm{C}$ is shown in Figure 9 (see Table S5 in Supplementary Materials). The deconvolution was performed based on the Doniach-Sunjic (DS) line shape [63]. Obviously, the iron line is rather weak due to the low iron content of the sample. The peaks around $708 \mathrm{eV}$ and $721 \mathrm{eV}$ can be assigned to overlapped states of $\mathrm{Fe}_{3} \mathrm{C}$ (cementite) and Fe with a dominant contribution of iron carbide $[61,62,64]$. The next two broad peaks around $710.6 \mathrm{eV}$ and $723.8 \mathrm{eV}$ are rather ascribed to $\gamma-\mathrm{FeOOH}$ (lepidocrocite) or/and $\alpha-\mathrm{FeOOH}$ (goethite) states $[65,66]$. According to previous studies, the binding energy difference between the two components is only $0.1 \mathrm{eV}[65,66]$. Considering the sensitivity of our spectrometer, which is about $0.3 \mathrm{eV}$, we are not able to precisely distinguish which component dominates in the studied material. Instead, we can deduce that it could be a convolution of the two species due to the broad peaks. There are also two additional satellite peaks. The relative contribution of each state estimated based on the deconvolution is about 31.3 at. $\%, 44.5$ at. $\%$, and 24.3 at. $\%$, respectively. Thus, it appears that based on the fit of the Fe2p photoemission line, the overlapping goethite/lepidocrocite states dominate that of cementite. However, one should be aware that a broad satellite structure may be composed of states assigned to both Fe-based contributions, and their ratio can be disturbed.

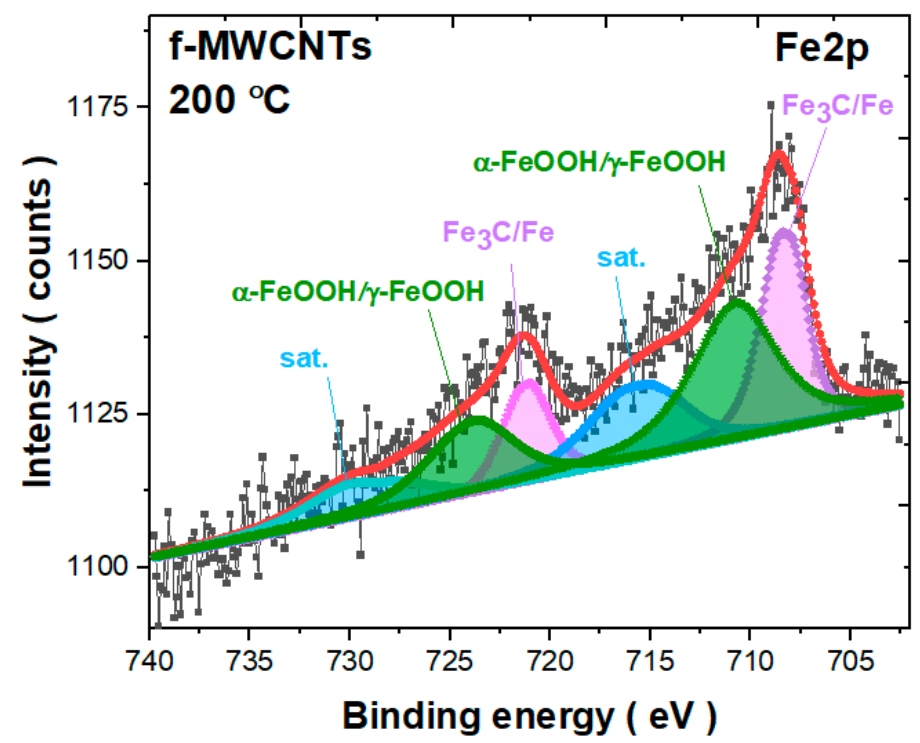

Figure 9. The Fe2p core level line for f-MWCNTs annealed at $200{ }^{\circ} \mathrm{C}$. 


\subsection{Magnetic Properties}

The thermal evolution of the magnetization measured under zero-field-cooled (ZFC) and field-cooled (FC) conditions under an applied field of $1 \mathrm{kOe}$ and 100 Oe is depicted in Figure 10. As one may notice, the magnetization is relatively lower for pristine nanotubes than for calcined ones. In addition, for calcined nanotubes, the modification of thermal dependence of magnetization seems to be independent of the calcination temperature. However, it is worth noting that the estimated difference $\mathrm{M}_{\mathrm{FC}}-\mathrm{M}_{\mathrm{ZFC}}$ is slightly dependent on calcination procedure from about $0.029 \mathrm{emu} / \mathrm{g}$ (pristine) to $0.048 \mathrm{emu} / \mathrm{g}$ (calcined at $300{ }^{\circ} \mathrm{C}$ ) and $0.031 \mathrm{emu} / \mathrm{g}$ (pristine) to $0.070 \mathrm{emu} / \mathrm{g}$ (calcined at $300{ }^{\circ} \mathrm{C}$ ) estimated at $100 \mathrm{Oe}$ and $1 \mathrm{kOe}$, respectively. Thus, the observed differences can probably be related to variation within Fe-based components modified over calcination. The difference in the ZFC and FC curves and their divergence above room temperature revealed some thermal blocking effects, usually attributed to magnetic anisotropy. Indeed, the maximum occurrence in ZFC curves can be associated with the blocking process of some Fe-complexes as nanoparticle catalyst residues. The observed $\mathrm{M}(\mathrm{T})$ variations are relatively consistent with previously published results [23,34]. Jamrozik et al. [34] revealed that the $\mathrm{M}(\mathrm{T})$ dependence at a lower temperature for all studied nanotubes is different than expected for pure cementite, suggesting the influence of additional iron-based species, which lead to a slight increase in magnetization with decreasing temperature. As the authors claim, the magnetization results demonstrate a predominant amount of iron in the ferromagnetically ordered (or in the form of superparamagnetic particles) cementite phase. Smaller magnetization values for MWCNTs samples than that of bulk $\mathrm{Fe}_{3} \mathrm{C}$ can also be caused by some additional diamagnetic elements such as oxygen present in the samples [23,34]. Indeed, as shown by XRD and XPS analysis, the diamagnetic elements are observed in all studied samples, but their relative contribution is reduced after calcination. Probably, therefore the magnetization is lower for pristine nanotubes than for annealed ones (see Figure 10). In addition, we also observe an evident increase in magnetization at the low-temperature range (below $20 \mathrm{~K}$ for $1 \mathrm{kOe}$ and below $12 \mathrm{~K}$ for $100 \mathrm{Oe}$ ), which points to the conclusion that probably in our samples, there are more than one Fe-based species.
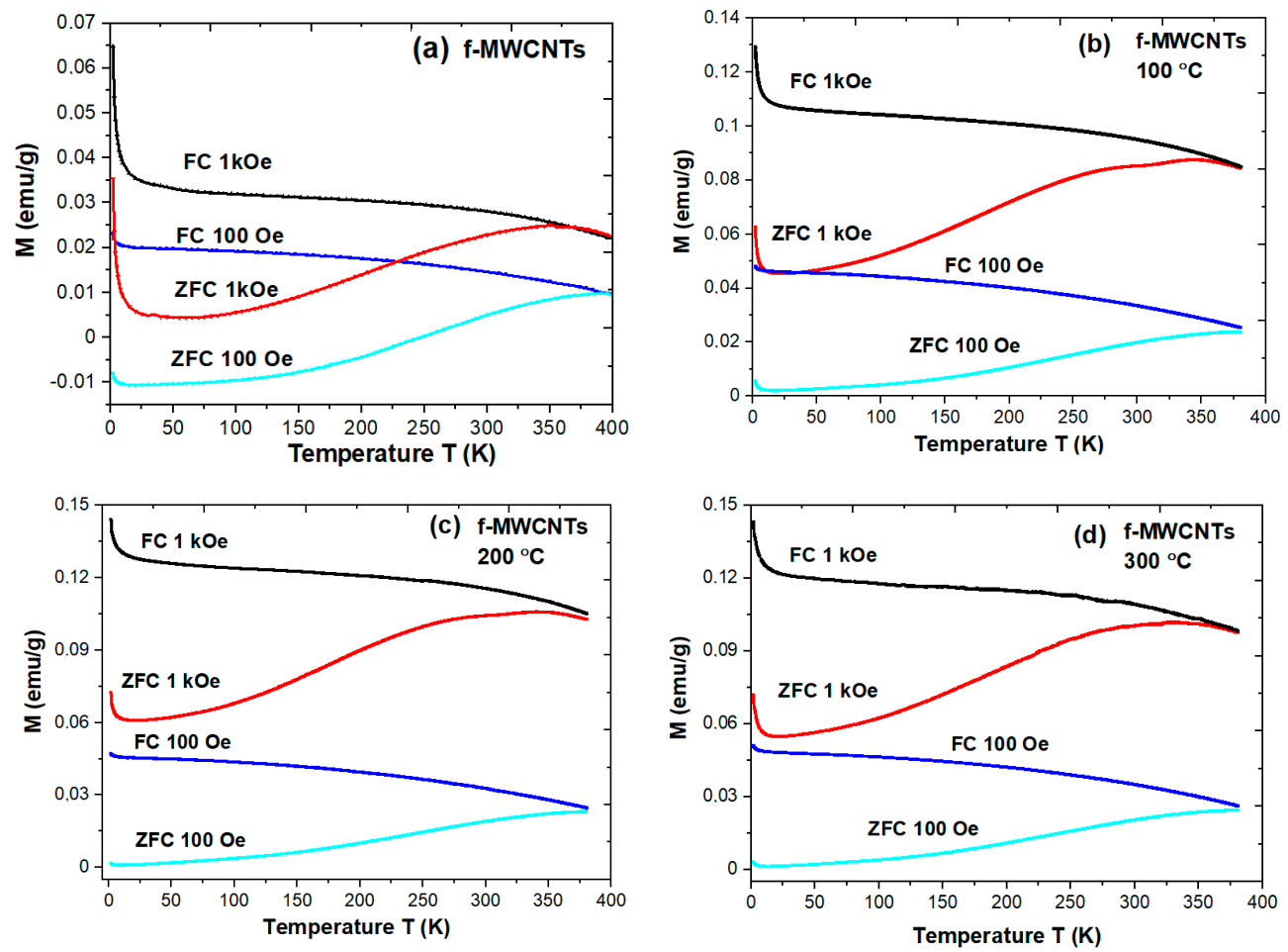

Figure 10. The thermomagnetic dependence of magnetization $\mathrm{M}(\mathrm{T})$ measured at $1 \mathrm{kOe}$ and 100 Oe for f-MWCNTs: (a) pristine; (b) calcined at $100{ }^{\circ} \mathrm{C}$; (c) calcined at $200{ }^{\circ} \mathrm{C}$; (d) calcined at $300{ }^{\circ} \mathrm{C}$. 
The $\mathrm{M}_{\mathrm{ZFC}}(\mathrm{T})$ high-temperature measurements performed for pristine and calcined at $300{ }^{\circ} \mathrm{C}$ nanotubes allow determining the phase transition temperature for magnetic component dominated in f-MWCNTs. Between 400-500 K, the evident phase transition can be noted. The performed $\mathrm{dM} / \mathrm{dT}$ differentiation allows estimating the value of the Curie temperature, which equals $\mathrm{T}_{\mathrm{C}} \approx 452 \pm 15 \mathrm{~K}$. As previously discussed, in the studies samples, we can distinguish several types of Fe-based structures with the evident influence of $\mathrm{Fe}_{3} \mathrm{C}$. Cementite is a metallic ferromagnet transforming to the paramagnetic state at a Curie temperature of about $\mathrm{T}_{C}=483 \mathrm{~K}$ [67]. In our case, such temperature is lower, but as evidenced, the presence of other magnetic Fe-based components cannot be neglected. Indeed, Lee et al. [68] revealed the magnetic phase transition for goethite $(\alpha-\mathrm{FeOOH})$ and lepidocrocite $(\gamma-\mathrm{FeOOH})$ nanoparticles. Both crystallize in the orthorhombic structure and show the antiferromagnetic arrangement with the Néel temperature $\mathrm{T}_{\mathrm{N}}=252 \mathrm{~K}$ and $53 \mathrm{~K}$, respectively. Such values are lower than bulk materials, e.g., for bulk $\alpha$-FeOOH, it equals about $\mathrm{T}_{\mathrm{N}}=372 \mathrm{~K}$ [69]. Thus, the origin of the broad peak observed for f-MWCNTs may comprise the overlapped magnetic phase transition of dominated cementite and partly goethite. The influence of lepidocrocite is low and can be noted by a weak inflexion point around $50 \mathrm{~K}$. However, there is an additional peculiarity between $750 \mathrm{~K}$ and $850 \mathrm{~K}$ as the induced heat-treatment phase transition during heating the sample under measurements conditions above $300 \mathrm{~K}$. As evidenced by Boi et al. [70], the decomposition of $\gamma$-Fe into $\alpha$-Fe starts even at temperatures below $200{ }^{\circ} \mathrm{C}$ and is significantly faster in the temperature range of 300-399 ${ }^{\circ} \mathrm{C}$. However, such a phenomenon occurs in a strictly controlled environment without possible oxidation. The magnetic transition presented in Figure 11 at high temperatures is lower than for typical $\alpha$-Fe, which may indicate that the Fe-oxides are probably generated during measurements.

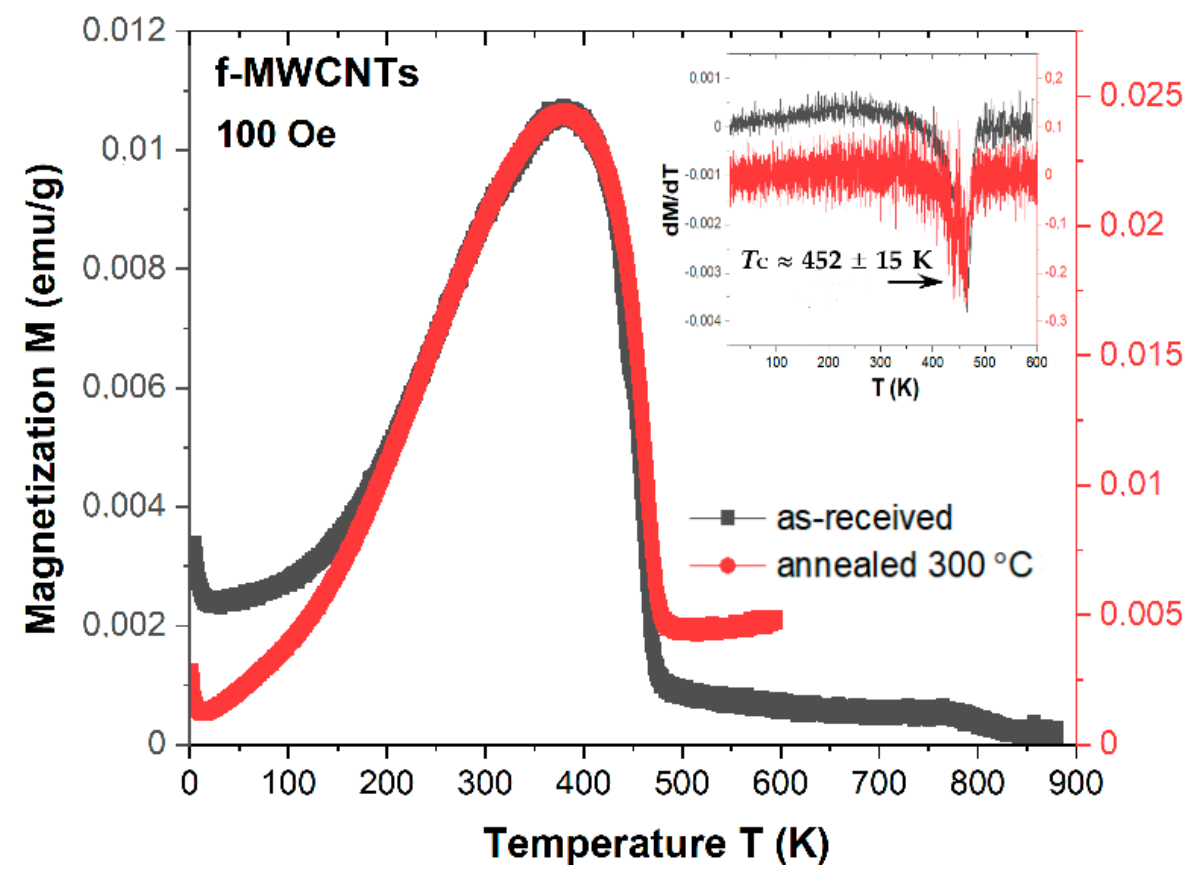

Figure 11. The ZFC dependence of magnetization $\mathrm{M}(\mathrm{T})$ measured at 100 Oe for $\mathrm{f}-\mathrm{MWCNTs}$ and calcined at $300^{\circ} \mathrm{C}$. Inset shows the $\mathrm{dM} / \mathrm{dT}$ vs. T dependence.

The analysis of hysteresis loops was conducted at $2 \mathrm{~K}, 100 \mathrm{~K}$, and $300 \mathrm{~K}$ (see Figure 12). Generally, all studied samples revealed ferromagnetic-like behaviour with evident coercivity $\left(\mathrm{H}_{\mathrm{C}}\right)$ and some diamagnetic contribution. The first one is evidence of Fe-based nano-components, while the latter may originate from non-magnetic carbon and functional groups component as well as the possible influence of the sample holder. In order to estimate saturation magnetization just dependent on Fe species present in the sample, the diamagnetic component can be separated from the ferromagnetic one. Such separation 
can be achieved by subtracting the diamagnetic part by linear fitting of $\mathrm{M}(\mathrm{H})$ at a higher field. Using such an approach, we can distinguish the magnetization values at the highest applied external field (placed in Table 2 as $\mathrm{M}_{7 \mathrm{~T}}$ for pristine and $\mathrm{M}_{9 \mathrm{~T}}$ for calcined nanotubes) and the values of saturation magnetization $\mathrm{M}_{\mathrm{S}}$ of the ferromagnetic component as the extrapolation, which is obviously different. Thus, the analysis of saturation magnetization values shows a significant difference between pristine and calcined samples, where M.S. differs almost by order of magnitude. Nevertheless, for all calcined samples, such value is almost the same (see Table 2). The shape of hysteresis loops reveals a small deformation at $300 \mathrm{~K}$ for pristine and $100{ }^{\circ} \mathrm{C}$ for calcined nanotubes and even more noticeable at $200{ }^{\circ} \mathrm{C}$ and $300{ }^{\circ} \mathrm{C}$ for calcined nanotubes at just $2 \mathrm{~K}$. The observed deformation can be associated with various Fe-based components and their exchange coupling behaviour.

Concomitantly, the magnetization process is sensitive to the synthesis type and purification and functionalization process of nanotubes. As previously published, e.g., by Lipert et al. [71], the magnetic properties of CNTs prepared with magnetic catalyst material are determined by the ferromagnetic or superparamagnetic catalyst particles formed during synthesis and remaining inside carbon nanotubes after such process. As reported during the synthesis of CNTs, some catalyst particles are encapsulated into nanotubes forming a single magnetic domain and, in this way, enhancing the coercivity of nanotubes. Such phenomena were observed in pure and functionalized nanotubes and their composites $[5,26]$. The value of coercivity estimated based on hysteresis loops is reduced upon calcination from $1.77 \mathrm{kOe}$ (pristine f-MWCNTs) to $0.63 \mathrm{kOe}$ (calcined at $300{ }^{\circ} \mathrm{C}$ f-MWCNTs). Such a reduction is also well seen at $100 \mathrm{~K}$, but at room temperature, coercivity seems to be relatively stable (see Table 2 ). The observed modification of coercivity is probably related to various Fe-based species. Generally, for nanocrystalline $\mathrm{Fe}_{3} \mathrm{C}$ with a particle size of about $22 \pm 4 \mathrm{~nm}$, the $\mathrm{H}_{\mathrm{C}}$ estimated at $300 \mathrm{~K}$ is about $0.173 \mathrm{kOe}$ [72]. It is worth noting that for nanocrystalline $\mathrm{Fe}_{3} \mathrm{C}$, the magnetization is lower than for bulk specimens due to the smaller value of particles size [72].
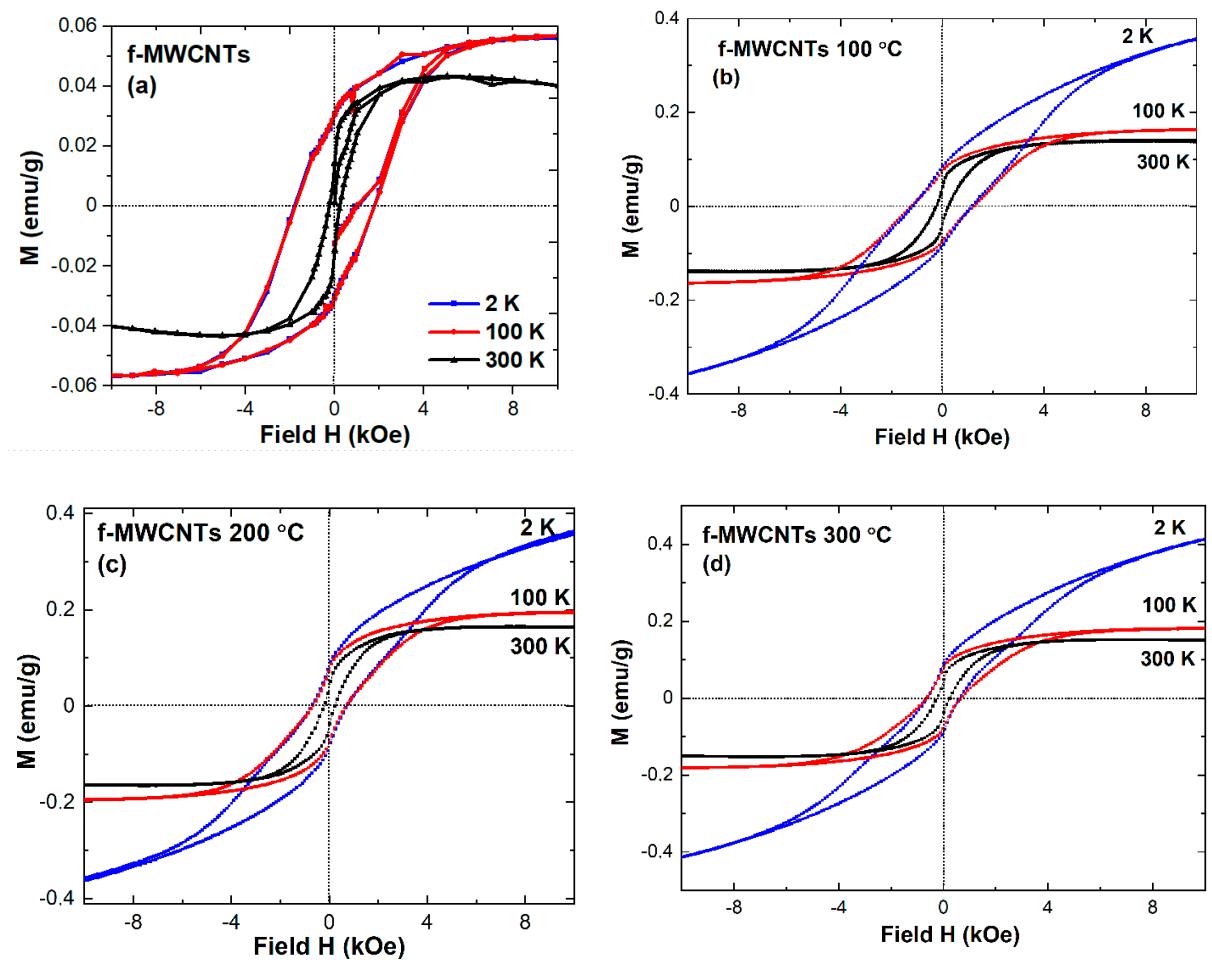

Figure 12. Hysteresis loops $M(H)$ measured at $2 \mathrm{~K}, 100 \mathrm{~K}$, and $300 \mathrm{~K}$ for f-MWCNTs: (a) pristine; (b) calcined at $100{ }^{\circ} \mathrm{C}$; (c) calcined at $200{ }^{\circ} \mathrm{C}$; (d) calcined at $300{ }^{\circ} \mathrm{C}$. 
Table 2. Magnetic properties of pristine and calcined f-MWCNTs.

\begin{tabular}{|c|c|c|c|c|c|c|c|c|c|c|c|c|}
\hline \multirow{3}{*}{$\begin{array}{c}\text { Samples } \\
f- \\
\text { MWCNTs } \\
\text { pristine }\end{array}$} & \multicolumn{4}{|c|}{$2 \mathrm{~K}$} & \multicolumn{4}{|c|}{$100 \mathrm{~K}$} & \multicolumn{4}{|c|}{$300 \mathrm{~K}$} \\
\hline & $\begin{array}{c}\mathrm{M}_{7 \mathrm{~T}} \\
(\mathrm{emu} / \mathrm{g}) \\
\pm 0.006\end{array}$ & $\begin{array}{c}\mathrm{M}_{\mathrm{S}} \\
(\mathrm{emu} / \mathrm{g}) \\
\pm 0.006\end{array}$ & $\begin{array}{c}\mathrm{M}_{\mathrm{R}} \\
(\mathrm{emu} / \mathrm{g}) \\
\pm 0.006\end{array}$ & $\begin{array}{c}\text { Hc } \\
\text { (kOe) } \\
\pm 0.005\end{array}$ & $\begin{array}{c}\mathrm{M}_{7 \mathrm{~T}} \\
(\mathrm{emu} / \mathrm{g}) \\
\pm 0.006\end{array}$ & $\begin{array}{c}\mathrm{M}_{\mathrm{S}} \\
(\mathrm{emu} / \mathrm{g}) \\
\pm 0.006\end{array}$ & $\begin{array}{c}\mathrm{M}_{\mathrm{R}} \\
(\mathrm{emu} / \mathrm{g}) \\
\pm 0.006\end{array}$ & $\begin{array}{c}\mathrm{Hc} \\
\text { (kOe) } \\
\pm 0.005\end{array}$ & $\begin{array}{c}\mathrm{M}_{7 \mathrm{~T}} \\
(\mathrm{emu} / \mathrm{g}) \\
\pm 0.006\end{array}$ & $\begin{array}{c}\mathrm{M}_{\mathrm{S}} \\
(\mathrm{emu} / \mathrm{g}) \\
\pm 0.006\end{array}$ & $\begin{array}{c}\mathrm{M}_{\mathrm{R}} \\
\text { (emu/g) } \\
\pm 0.006\end{array}$ & $\begin{array}{c}\mathrm{Hc} \\
\text { (kOe) } \\
\pm 0.005\end{array}$ \\
\hline & 0.02 & 0.07 & 0.03 & 1.77 & 0.02 & 0.07 & 0.031 & 1.78 & -0.04 & 0.05 & 0.01 & 0.24 \\
\hline $\begin{array}{c}\mathrm{f}- \\
\text { MWCNTs } \\
\text { calcined }\end{array}$ & $\begin{array}{c}\mathrm{M}_{9 \mathrm{~T}} \\
(\mathrm{emu} / \mathrm{g}) \\
\pm 0.006\end{array}$ & $\begin{array}{c}\mathrm{M}_{\mathrm{S}} \\
(\mathrm{emu} / \mathrm{g}) \\
\pm 0.006\end{array}$ & $\begin{array}{c}\mathrm{M}_{\mathrm{R}} \\
(\mathrm{emu} / \mathrm{g}) \\
\pm 0.006\end{array}$ & $\begin{array}{c}\text { Hc } \\
\text { (kOe) } \\
\pm 0.02\end{array}$ & $\begin{array}{c}\mathrm{M}_{9 \mathrm{~T}} \\
(\mathrm{emu} / \mathrm{g}) \\
\pm 0.006\end{array}$ & $\begin{array}{c}\mathrm{M}_{\mathrm{S}} \\
(\mathrm{emu} / \mathrm{g}) \\
\pm 0.006\end{array}$ & $\begin{array}{c}\mathrm{M}_{\mathrm{R}} \\
(\mathrm{emu} / \mathrm{g}) \\
\pm 0.006\end{array}$ & $\begin{array}{c}\mathrm{Hc} \\
\text { (kOe) } \\
\pm 0.02\end{array}$ & $\begin{array}{c}\mathrm{M}_{9 \mathrm{~T}} \\
(\mathrm{emu} / \mathrm{g}) \\
\pm 0.006\end{array}$ & $\begin{array}{c}\mathrm{M}_{\mathrm{S}} \\
(\mathrm{emu} / \mathrm{g}) \\
\pm 0.006\end{array}$ & $\begin{array}{c}\mathrm{M}_{\mathrm{R}} \\
(\mathrm{emu} / \mathrm{g}) \\
\pm 0.006\end{array}$ & $\begin{array}{c}\text { Hc } \\
\text { (kOe) } \\
\pm 0.02\end{array}$ \\
\hline $\begin{array}{l}100^{\circ} \mathrm{C} \\
200^{\circ} \mathrm{C} \\
300^{\circ} \mathrm{C}\end{array}$ & $\begin{array}{l}0.40 \\
0.54 \\
0.51\end{array}$ & $\begin{array}{l}0.53 \\
0.47 \\
0.63\end{array}$ & $\begin{array}{l}0.08 \\
0.08 \\
0.09\end{array}$ & $\begin{array}{l}1.18 \\
0.74 \\
0.63\end{array}$ & $\begin{array}{l}0.07 \\
0.11 \\
0.05\end{array}$ & $\begin{array}{l}0.19 \\
0.22 \\
0.21\end{array}$ & $\begin{array}{l}0.08 \\
0.08 \\
0.08\end{array}$ & $\begin{array}{l}1.23 \\
0.69 \\
0.65\end{array}$ & $\begin{array}{c}0.01 \\
0.01 \\
-0.03\end{array}$ & $\begin{array}{l}0.16 \\
0.19 \\
0.18\end{array}$ & $\begin{array}{l}0.39 \\
0.40 \\
0.44\end{array}$ & $\begin{array}{l}0.26 \\
0.22 \\
0.24\end{array}$ \\
\hline
\end{tabular}

In our case, for pristine $\mathrm{f}-\mathrm{MWCNTs}$ at $300 \mathrm{~K}$, we estimated the $\mathrm{H}_{\mathrm{C}}$ value as about $0.238 \mathrm{kOe}$, which is slightly higher than the value observed for pure cementite. As further evidence, we have more than one iron type in the studied nanotubes. So far, the value of coercivity for nanotubes was also estimated by Jamrozik et al. [34], who showed that for MWCNTs-COOH, the coercivity is varied from about $2 \mathrm{kOe}(3 \mathrm{~K})$ to $0.28 \mathrm{kOe}(295 \mathrm{~K})$. The latter studies performed by Jamrozik et al. [40] for control and as-milled MWCNTs$\mathrm{COONH}_{4}$ nanotubes demonstrate the value of $\mathrm{H}_{\mathrm{C}}$ as about $1.24 \mathrm{kOe}(3 \mathrm{~K})$ and $0.27 \mathrm{kOe}$ $(295 \mathrm{~K})$ for as-prepared specimens. Thus, the values noted by us (see Table 2) are in reasonably good agreement with those recently published. The authors revealed that milling has a slight influence on coercivity. However, the variation of magnetization compared in as-prepared and milled samples can be affected by changes within iron phases, their individual content, and chemical composition. The contribution of various iron species was determined by the Mössbauer spectrometry.

\subsection{Mössbauer Spectrometry}

The main objective of using ${ }^{57} \mathrm{Fe}$ Mössbauer spectrometry is to determine the form of iron in the studied nanotubes, but the first difficulty has related to the preparation of the Mössbauer sample due to the low content of Fe. The measurements carried out with a very intense radioactive source (about $1.6 \mathrm{GBq}$ ) only at $77 \mathrm{~K}$, required about two weeks registration time to obtain good statistics, as shown in Figure 13 with the relative transmission scale. The hyperfine structure of the pristine f-MWCNTs consists of a single predominant line, a magnetic sextet, and a quadrupolar doublet. The refined values of the hyperfine parameters of these three components are listed in Table 3 and allow us to assign them unambiguously to $\gamma$-Fe, cementite, and some $\mathrm{Fe}^{3+}$ oxide phase, respectively. After annealing at $300{ }^{\circ} \mathrm{C}$, the main difference is due to the presence of an additional magnetic sextet attributed to a $\mathrm{Fe}^{3+}$ oxide phase. A rigorous analysis leads to attributing the quadrupolar doublet and the second magnetic sextet to goethite nanoparticles. Nevertheless, at this stage, in agreement with previous XPS results, the presence of some traces of lepidocrocite $(\gamma-\mathrm{FeOOH})$, which exhibit rather similar values of hyperfine parameters in the paramagnetic state, cannot be excluded. Indeed, it can be concluded that the conditions of synthesis favor the emergence of some $\gamma$-Fe (nano)particles probably embedded in a goethite shell after oxidation, in addition to cementite grains and goethite nanoparticles (probably smaller than about $10 \mathrm{~nm}$ ). In contrast, annealing at $300^{\circ} \mathrm{C}$ should favour the aggregation of the goethite nanoparticles, giving rise to larger magnetically blocked nanoparticles of goethite. However, it is essential to note some disagreements in the estimated proportions in the pristine and annealed samples: they can be attributed not only to the differences in the Lamb-Mössbauer factors of the three components, but it must also be taken into account that the errors are amplified due to the very low content of Fe. However, it is very important to note that the present results agree quantitatively with those presented earlier [34-40]. 

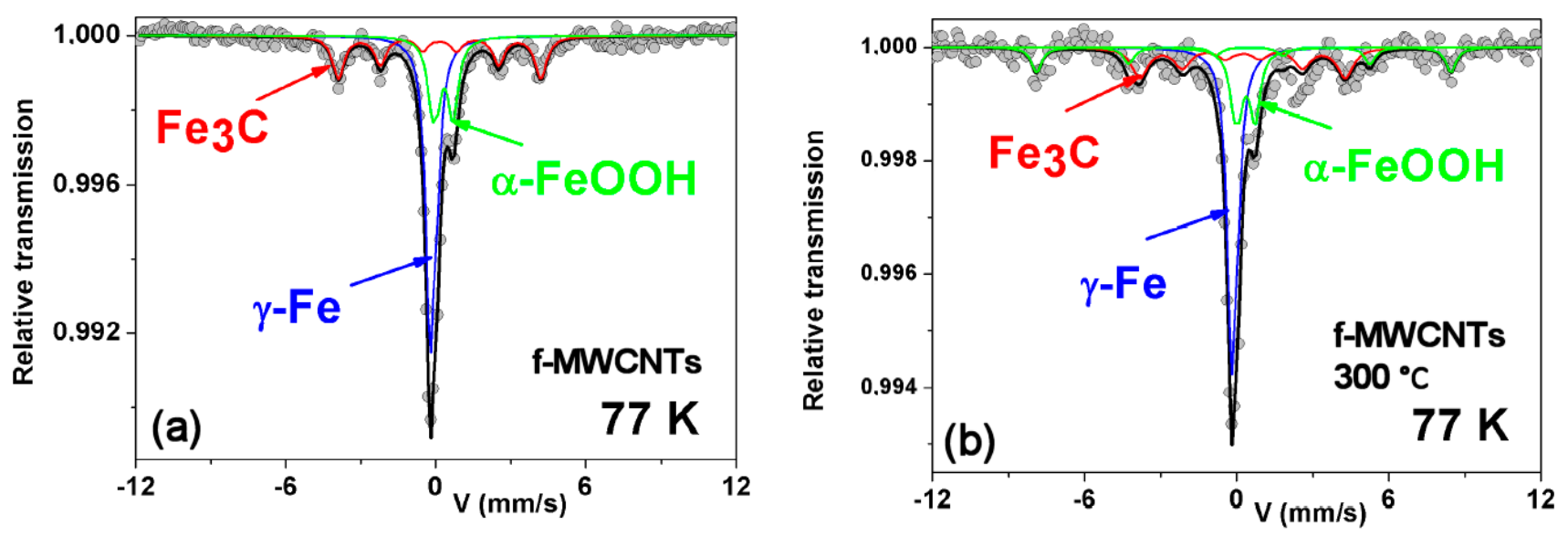

Figure 13. Mössbauer spectra measured at $77 \mathrm{~K}$ for f-MWCNTs: (a) as-received; (b) calcined at $300{ }^{\circ} \mathrm{C}$.

Table 3. Refined values of hyperfine Mössbauer parameters in pristine and calcined f-MWCNTs determined at $77 \mathrm{~K}: \delta$ : isomer shift; $\Gamma$ : full width at half height; $\Delta$ : quadrupolar splitting; $2 \varepsilon$ : quadrupolar shift; $\mathrm{B}_{\mathrm{hf}}$ : hyperfine field.

\begin{tabular}{|c|c|c|c|c|c|c|}
\hline Samples & & & & & & \\
\hline \multirow{2}{*}{$\begin{array}{l}\text { f-MWCNTs } \\
\text { pristine }\end{array}$} & $\begin{array}{c}\delta \\
(\mathrm{mm} / \mathrm{s}) \\
\pm 0.02\end{array}$ & $\begin{array}{c}\Gamma \\
(\mathrm{mm} / \mathrm{s}) \\
\pm 0.02\end{array}$ & $\begin{array}{c}\Delta \text { or } 2 \varepsilon \\
(\mathrm{mm} / \mathrm{s}) \\
\pm 0.02\end{array}$ & $\begin{array}{l}\mathbf{B}_{\mathrm{hf}} \\
(\mathrm{T}) \\
\pm 1.0\end{array}$ & $\begin{array}{l}(\%) \\
\pm 3\end{array}$ & Component \\
\hline & $\begin{array}{c}-0.01 \\
0.43 \\
0.37\end{array}$ & $\begin{array}{l}0.49 \\
0.68 \\
0.33 \\
\end{array}$ & $\begin{array}{l}0^{*} \\
0^{*} \\
0.90 \\
\end{array}$ & $\begin{array}{c}- \\
24.9 \\
-\end{array}$ & $\begin{array}{l}49 \\
32 \\
19\end{array}$ & $\begin{array}{c}\gamma-\mathrm{Fe} \\
\mathrm{Fe}_{3} \mathrm{C} \\
\alpha-\mathrm{FeOOH}\end{array}$ \\
\hline \multirow{2}{*}{$\begin{array}{l}\text { f-MWCNTs } \\
\text { calcined at } \\
300^{\circ} \mathrm{C}\end{array}$} & $\begin{array}{c}\delta \\
(\mathrm{mm} / \mathrm{s}) \\
\pm 0.02\end{array}$ & $\begin{array}{c}\Gamma \\
(\mathrm{mm} / \mathrm{s}) \\
\pm 0.02\end{array}$ & $\begin{array}{c}\Delta \text { or } 2 \varepsilon \\
(\mathrm{mm} / \mathrm{s}) \\
\pm 0.02\end{array}$ & $\begin{array}{l}\mathbf{B}_{\mathrm{hf}} \\
(\mathrm{T}) \\
\pm 1.0\end{array}$ & $\begin{array}{l}(\%) \\
\pm 3\end{array}$ & component \\
\hline & $\begin{array}{l}0.02 \\
0.44 \\
0.46 \\
0.50\end{array}$ & $\begin{array}{l}0.30 \\
0.77 \\
0.74 \\
0.50\end{array}$ & $\begin{array}{c}0^{*} \\
0.11 \\
0.70 \\
-0.22\end{array}$ & $\begin{array}{c}- \\
2 \overline{5.7} \\
- \\
5 \overline{0} .5\end{array}$ & $\begin{array}{l}41 \\
26 \\
20 \\
13\end{array}$ & $\begin{array}{c}\gamma-\mathrm{Fe} \\
\mathrm{Fe}_{3} \mathrm{C} \\
\alpha-\mathrm{FeOOH} \\
\alpha-\mathrm{FeOOH}\end{array}$ \\
\hline
\end{tabular}

\section{Conclusions}

This study presents the complete study of commercial f-MWCNTs functionalized by the $-\mathrm{COONH}_{4}$ group. We analyzed both pristine and calcined nanotubes using different and complementary techniques. As demonstrated, the Fe-base embedded nanoparticles as synthesis residues are responsible for the magnetic behaviour. Based on XRD and ${ }^{57} \mathrm{Fe}$ Mössbauer spectrometry, we have identified three main Fe-based species: $\gamma$-Fe, cementite $\left(\mathrm{Fe}_{3} \mathrm{C}\right)$, goethite $(\alpha-\mathrm{FeOOH})$. Diffraction analysis indicates an additional phase of lepidocrocite $(\gamma-\mathrm{FeOOH})$, which is also not excluded in the photoemission and Mössbauer studies. However, the amount of each constituent is low. The average size of NPs inside nanotubes is between 11-22 $\mathrm{nm}$. The Fe-based magnetic nanoparticles of cementite are blocked above room temperature, as shown by ZFC curves. The magnetic properties are slightly modified during the heat treatment due to the modification within iron components. From the thermomagnetic curves, the typical phase transition of cementite is observed. However, Mössbauer spectrometry revealed the domination of $\gamma$-Fe over $\mathrm{Fe}_{3} \mathrm{C}$ and $\alpha-\mathrm{FeOOH}$. Diffraction, Raman, and microscopic analysis show that the carbon graphene layers in the nanotubes are disordered due to the turbostratic form of the carbon. The photoemission studies showed almost stable states of the carbon but a significant modification in the nitrogen and oxygen groups as an effect of calcination. Indeed, the reduction in organic impurities during calcination is evident from the XRD pattern.

The performed multi-technique characterization of f-MWCNTs nanotubes provided sufficient information on their structural, magnetic, and spectroscopic behaviour. This analysis could be helpful for the design and development of nanocomposites based on nanotubes as functional materials with a wide range of applications. 
Supplementary Materials: The following are available online at https:/ / www.mdpi.com/article/ 10.3390/ma15030977/s1; Table S1: The results of C1s core level lines fit pristine and calcined fMWCNTs nanotubes; Table S2. The results of O1s core level lines fit pristine and calcined f-MWCNTs nanotubes; Table S3. The results of N1s core level lines fit pristine and calcined f-MWCNTs nanotubes; Table S4. The results of S2p core level lines fit pristine and calcined f-MWCNTs nanotubes; Table S5. The results of Fe2p core level lines fit for f-MWCNTs nanotubes calcined at $200^{\circ} \mathrm{C}$.

\begin{abstract}
Author Contributions: Conceptualization, A.B.; methodology, A.B., B.S. and B.L.; synthesis, B.L.; formal analysis, A.B., B.S., M.D., J.-M.G. and S.L.; investigation, A.B. (XRD, XPS, and magnetic measurements), M.D. (Raman spectroscopy), M.P. (TEM), S.L. and A.Ś.-W. (Magnetic measurements), and J.-M.G. and B.S. (Mössbauer spectroscopy); data curation, A.B., B.S., M.D., J.-M.G. and S.L.; writing-original draft preparation, A.B., M.D. and J.-M.G.; writing-review and editing, A.B., J.-M.G., S.L. and A.Ś.-W.; supervision, A.B. and J.-M.G.; project administration, A.B. All authors have read and agreed to the published version of the manuscript.
\end{abstract}

Funding: This research received no external funding.

Institutional Review Board Statement: Not applicable.

Informed Consent Statement: Not applicable.

Data Availability Statement: The data presented in this study are available on request from the corresponding author. The data are not publicly available due to restrictions of privacy.

Acknowledgments: B.S. would like to thank Erasmus + U.E. funds and the French Embassy in Poland, grant 15/2019, for the partial financial support of her internship at Le Mans University.

Conflicts of Interest: The authors declare no conflict of interest. The funders had no role in the design of the study; in the collection, analyses, or interpretation of data; in the writing of the manuscript; or in the decision to publish the results.

\title{
References
}

1. Iijima, S. Helical microtubules of graphitic carbon. Nature 1991, 354, 56-58. [CrossRef]

2. Baughman, R.H.; Zakhidov, A.A.; Heer, W.A. Carbon nanotubes-The route toward applications. Science 2002, 297, 787-792. [CrossRef] [PubMed]

3. Daenen, M.; de Fouw, R.D.; Hamers, B.; Janssen, P.G.A.; Schouteden, K.; Veld, M.A.J. The Wondrous Word of Carbon Nanotubes—A Review of Current Carbon Nanotube Technologies; Eindhoven University of Technology: Eindhoven, The Netherlands, 2003.

4. Pereira, C.; Costa, R.S.; Lopes, L.; Bachiller-Baeza, B.; Rodríguez-Ramos, I.; Guerrero-Ruiz, A.; Tavares, P.B.; Freire, C.; Pereira, A.M. Multifunctional mixed valence $\mathrm{N}$-doped $\mathrm{CNT} @ \mathrm{MFe}_{2} \mathrm{O}_{4}$ hybrid nanomaterials: From engineered one-pot coprecipitation to application in energy storage paper supercapacitors. Nanoscale 2018, 10, 12820-12840. [CrossRef]

5. Al Khabouri, S.; Al Harthi, S.; Maekawa, T.; Nagaoka, Y.; Elzain, M.E.; Al Hinai, A.; Al-Rawas, A.D.; Gismelseed, A.M.; Yousif, A.A. Composition, Electronic and Magnetic Investigation of the Encapsulated $\mathrm{ZnFe}_{2} \mathrm{O}_{4}$ Nanoparticles in Multiwall Carbon Nanotubes Containing Ni Residues. Nanoscale Res. Lett. 2015, 10, 262. [CrossRef] [PubMed]

6. Zhou, X.; Shen, L.; Li, L.; Zhou, S.; Huang, T.; Hu, C.; Pan, W.; Jing, X.; Sunc, J.; Gaod, L.; et al. Microwave sintering carbon nanotube/ $\mathrm{Ni}_{0.5} \mathrm{Zn}_{0.5} \mathrm{Fe}_{2} \mathrm{O}_{4}$ composites and their electromagnetic performance. J. Eur. Ceram. Soc. 2013, 33, 2119-2126. [CrossRef]

7. Cao, H.; Zhu, M.; Li, Y.; Liu, J.; Ni, Z.; Qin, Z. A highly coercive carbon nanotube coated with $\mathrm{Ni}_{0.5} \mathrm{Zn}_{0.5} \mathrm{Fe}_{2} \mathrm{O}_{4}$ nanocrystals synthesized by chemical precipitation-hydrothermal process. J. Solid State Chem. 2007, 180, 3218-3223. [CrossRef]

8. Salarizadeh, N.; Sadri, M.; Hosseini, H.; Sajedi, R.H. Synthesis and physicochemical characterization of $\mathrm{Ni}_{\mathrm{x}} \mathrm{Zn}_{1-\mathrm{x}} \mathrm{Fe}_{2} \mathrm{O}_{4} / \mathrm{MWCNT}$ nanostructures as enzyme mimetics with peroxidase-like catalytic activity. Carbon Lett. 2017, 24, 103-110.

9. Chen, Y.; Wang, X.; Zhang, Q.; Li, Y.; Wang, H. Synthesis and characterization of MWCNTs/Co1-xZnxFe2O4 magnetic nanocomposites and their use in hydrogels. J. Alloys Compd. 2011, 509, 4053-4059. [CrossRef]

10. Zhou, X.; Han, Y.-H.; Zhang, Y.; Wang, Q.; Zhou, J.; Shen, L.; Huang, T.; Pan, W.; Xiang, C.; Tang, H.; et al. Ferrite multiphase/carbon nanotube composites sintered by spark plasma sintering. J. Ceram. Soc. Jpn. 2014, 122, 68-771. [CrossRef]

11. Murzata, G.; Ahmad, I.; Hakeem, A.; Mao, P.; Guohua, X.; Farid, M.T.; Mustafa, G.; Kanwal, M.; Hussain, M. Effect of multi-walled carbon nanotubes in the structural and magnetic properties of Mn-Zn ferrite. Dig. J. Nanomater. Biostructures 2015, 10, 1393-1401.

12. Rigo, C.; da Cruz Severo, E.; Mazutti, M.A.; Dotto, G.L.; Jahn, S.L.; Gündel, A.; Lucchese, M.M.; Chiavone-Filho, O.; Foletto, E.L. Preparation of Nickel Ferrite/Carbon Nanotubes Composite by Microwave Irradiation Technique for Use as Catalyst in PhotoFenton Reaction. Mater. Res. 2017, 20,311-316. [CrossRef]

13. Teber, A.; Cil, K.; Yilmaz, T.; Eraslan, B.; Uysal, D.; Surucu, G.; Baykal, A.H.; Bansal, R. Manganese and Zinc Spinel Ferrites Blended with Multi-Walled Carbon Nanotubes as Microwave Absorbing Materials. Aerospace 2017, 4, 2. [CrossRef]

14. Bahgat, M.; Ali Farghali, A.; El Rouby, W.; Khedr, M.; Mohassab-Ahmed, M.Y. Adsorption of methyl green dye onto multi-walled carbon nanotubes decorated with Ni nanoferrite. Appl. Nanosci. 2013, 3, 251-261. [CrossRef] 
15. Zampiva, R.Y.S.; Junior, C.G.K.; Pinto, J.S.; Panta, P.C.; Alves, A.K.; Bergmann, C.P. 3D CNT macrostructure synthesis catalyzed by $\mathrm{MgFe}_{2} \mathrm{O}_{4}$ nanoparticles-A study of surface area and spinel inversion influence. Appl. Surf. Sci. 2017, 422, 321-330. [CrossRef]

16. Dyke, C.A.; Tour, J.M. Overcoming the insolubility of carbon nanotubes through high degrees of sidewall functionalization. Chem. Eur. J. 2004, 10, 813-817. [CrossRef]

17. Ruelle, B.; Felten, A.; Ghijsen, J.; Drube, W.; Johnson, R.L.; Liang, D.; Erni, R.; Van Tendeloo, G.; Peeterbroeckb, S.; Dubois, P.; et al. Functionalization of MWCNTs with atomic nitrogen. Micron 2009, 40, 85-88. [CrossRef]

18. Kundu, S.; Xia, W.; Busser, W.; Becker, M.; Schmidt, D.A.; Havenith, M.; Muhler, M. The formation of nitrogen-containing functional groups on carbon nanotube surfaces: A quantitative XPS and TPD study. Phys. Chem. Chem. Phys. 2010, 12, 4351-4435. [CrossRef]

19. Okpalugo, T.I.T.; Papakonstantinou, P.; Murphy, H.; McLaughlin, J.; Brown, N.M.D. High resolution XPS characterization of chemical functionalized MWCNTs and SWCNTs. Carbon 2005, 43, 153-161. [CrossRef]

20. Yun, S.-M.; Kim, J.-W.; Jung, M.-J.; Nho, Y.-C.; Kang, P.-H.; Lee, Y.-S. An XPS Study of Oxyfluorinated Multiwalled Carbon Nano Tubes. Carbon Lett. 2007, 8, 292-298. [CrossRef]

21. Wepasnick, K.A.; Smith, B.A.; Bitter, J.L.; Fairbrother, D.H. Chemical and structural characterization of carbon nanotube surfaces. Anal. Bioanal. Chem. 2010, 396, 1003-1014. [CrossRef]

22. Jang, M.-H.; Sik Hwang, Y. Effects of functionalized multi-walled carbon nanotubes on toxicity and bioaccumulation of lead in Daphnia magna. PLoS ONE 2018, 13, e0194935. [CrossRef]

23. Tomczyk, M.M.; Boncel, S.; Herman, A.; Krawczyk, T.; Jakóbik-Kolon, A.; Pawlyta, M.; Krzywiecki, M.; Chrobak, A.; Minoshima M.; Sugihara, F.; et al. Oxygen Functional Groups on MWCNT Surface as Critical Factor Boosting T2 Relaxation Rate of Water Protons: Towards Improved CNT-Based Contrast Agents. Int. J. Nanomed. 2020, 15, 7433-7450. [CrossRef]

24. Mohl, M.; Kónya, Z.; Kukovecz, Á.; Kiricsi, I. Functionalization of Multi-Walled Carbon Nanotubes (MWCNTs) in Functionalized Nanoscale Materials, Devices and Systems. In Functionalized Nanoscale Materials, Devices and Systems. NATO Science for Peace and Security Series B: Physics and Biophysics; Vaseashta, A., Mihailescu, I.N., Eds.; Springer: Dordrecht Germany, 2008 ; pp. 365-368.

25. Lipińska, M.E.; Rebelo, S.L.H.; Pereira, M.F.R.; Gomes, J.A.N.F.; Freire, C.; Figueiredo, J.L. New insights into the functionalization of multi-walled carbon nanotubes with aniline derivatives. Carbon 2012, 50, 3280-3294. [CrossRef]

26. Bajorek, A.; Liszka, B.; Szostak, B.; . Pawlyta, M. Microstructure and magnetism of $\mathrm{Ni}_{0.5} \mathrm{Zn}_{0.5} \mathrm{Fe}_{2} \mathrm{O}_{4} /$ MWCNTs nanocomposites. J. Magn. Magn. Mater. 2020, 503, 166634. [CrossRef]

27. Baker, R.T.K.; Harris, P.S.; Thomas, R.B.; Waite, R.J. Formation of filamentous carbon from iron, cobalt and chromium catalyzed decomposition of acetylene. J. Catal. 1973, 30, 86-95. [CrossRef]

28. Sacco, A., Jr.; Thacker, P.; Chang, T.N.; Chiang, A.T.S. The initiation and growth of filamentous carbon from $\alpha$-iron in $\mathrm{H}_{2}, \mathrm{CH}_{4}$ $\mathrm{H}_{2} \mathrm{O}, \mathrm{CO}_{2}$, and $\mathrm{CO}$ gas mixtures. J. Catal. 1984, 85, 224-236. [CrossRef]

29. De Bokx, P.K.; Kock, A.J.H.M.; Boellaard, E.; Klop, W.; Geus, J.W. The formation of filamentous carbon on iron and nickel catalysts: I. Thermodynamics. J. Catal. 1985, 96, 454-467. [CrossRef]

30. Kock, A.J.H.M.; de Bokx, P.K.; Boellaard, E.; Klop, W.; Geus, J.W. The formation of filamentous carbon on iron and nickel catalysts: II. Mechanism. J. Catal. 1985, 96, 468-480. [CrossRef]

31. Schaper, A.K.; Hou, H.; Greiner, A.; Phillipp, F. The role of iron carbide in multi-walled carbon nanotube growth. J. Catal. 2004, 222, 250-254. [CrossRef]

32. Bondino, F.; Magnano, E.; Ciancio, R.; Castellarin-Cudia, C.; Barla, E.C.A.; Yakhou-Harris, F.; Rupesinghe, N.; Cepek, C. Stable Fe Nanomagnets Encapsulated Inside Vertically-Aligned Carbon Nanotubes. Phys. Chem. Chem. Phys. 2017, 19, 32079-32085. [CrossRef]

33. Zhang, X.; Wen, G.H.; Huang, S.; Dai, L.; Gao, R.; Wang, Z.L. Magnetic properties of Fe nanoparticles trapped at the tips of the aligned carbon nanotubes. J. Magn. Magn. Mater. 2001, 231, 9-12. [CrossRef]

34. Jamrozik, A.; Mazurkiewicz, M.; Małolepszy, A.; Stobiński, L.; Matlak, K.; Korecki, J.; Kurzydłowski, K.J.; Burda, K. Mössbauer spectroscopy analysis of iron compounds in carboxylated multiwall carbon nanotubes and their ammonium salt. Phys. Status Solidi A 2011, 208, 1783-1786. [CrossRef]

35. Perez-Cabero, M.; Taboada, J.B.; Guerrero-Ruiz, A.; Overweg, A.R.; Rodriguez-Ramos, I. The role of alpha-iron and cementite phases in the growing mechanism of carbon nanotubes: A ${ }^{57}$ Fe Mössbauer spectroscopy study. Phys. Chem. Chem. Phys. 2006, 8 , 230-1235. [CrossRef]

36. Prados, C.; Crespo, P.; González, J.M.; Hernando, A.; Marco, J.F.; Gancedo, R.; Grobert, N.; Terrones, M.; Walton, R.M.; Kroto, H.W. Hysteresis shift in Fe-filled carbon nanotubes due to $\gamma$-Fe. Phys. Rev. B Condens. Matter 2002, 65, 113405. [CrossRef]

37. Ruskov, T.; Spirov, I.; Ritschel, M.; Müller, C.; Leonhardt, A.; Ruskov, R. Mössbauer morphological analysis of Fe-filled multiwalled carbon nanotube samples. J. Appl. Phys. 2006, 100, 084326. [CrossRef]

38. Jamrozik, A.; Przewoźnik, J.; Mazurkiewicz, M.; Małolepszy, A.; Stobiński, A.; Trykowski, G.; Habina, I.; Matlak, K.; Korecki, J.; Kapusta, C.; et al. Influence of iron contaminations on local and bulk magnetic properties of nonfunctionalized and functionalized multi-wall carbon nanotubes. Phys. Status Solidi A 2014, 211, 661-669. [CrossRef]

39. Luberda-Durnaś, K.; Nieznalska, M.; Mazurkiewicz, M.; Małolepszy, A.; Khachataryan, G.; Khachataryan, K.; Tomasik, P.; Michalski, O.; Matlak, K.; Korecki, J.; et al. Studies of Fe-binding sites within multiwall carbon nanotubes using Mössbauer spectroscopy. Phys. Status Solidi A 2011, 208, 1796-1800. [CrossRef] 
40. Jamrozik, A.; Przewoźnik, J.; Krysiak, S.; Korecki, J.; Trykowski, G.; Małolepszy, A.; Burda, K. Effect of grinding and the mill type on magnetic properties of carboxylated multiwall carbon nanotubes. Materials 2021, 14, 4057. [CrossRef]

41. Li, Z.Q.; Lu, C.J.; Xia, Z.P.; Zhou, Y.; Luo, Z. X-ray diffraction patterns of graphite and turbostratic carbon. Carbon 2007, 45, 1686-1695. [CrossRef]

42. Ci, L.; Wei, B.; Xu, C.; Liang, J.; Wu, D.; Xie, S.; Zhou, W.; Li, Y.; Liu, Z.; Tang, D. Crystallization behavior of the amorphous carbon nanotubes prepared by the CVD method. J. Cryst. Growth 2001, 233, 823-828. [CrossRef]

43. Qiu, Y.; Gao, L. Chemical synthesis of turbostratic carbon nitride, containing C-N crystallites, at atmospheric pressure. Chem. Commun. 2003, 9, 2378-2379. [CrossRef]

44. He, Z.; Maurice, J.-L.; Gohier, A.; Lee, C.S.; Pribat, D.; Cojocaru, C.S. Iron Catalysts for the Growth of Carbon Nanofibers: Fe, Fe3C or Both? Chem. Mater. 2011, 23, 5379-5387. [CrossRef]

45. Wirth, C.T.; Bayer, B.C.; Gamalski, A.D.; Esconjauregui, S.; Weatherup, R.S.; Ducati, C.; Baehtz, C.; Robertson, J.; Hofmann, S. The Phase of Iron Catalyst Nanoparticles during Carbon Nanotube Growth. Chem. Mater. 2012, 24, 4633-4640. [CrossRef]

46. Jourdain, V.; Bichara, C. Current understanding of the growth of carbon nanotubes in catalytic chemical vapour deposition. Carbon 2013, 58, 2-39. [CrossRef]

47. Heise, H.M.; Kuckuk, R.; Ojha, A.K.; Srivastava, A.; Srivastava, V.; Asthana, B.P. Characterization of carbonaceous materials using Raman spectroscopy: A comparison of carbon nanotube filters, single- and multi-walled nanotubes, graphitized porous carbon and graphite. J. Raman Spectrosc. 2009, 40, 344-353. [CrossRef]

48. Shanov, V.; Yun, Y.-H.; Shultz, M.J. Synthesis and characterization of carbon nanotube materials (review). J. Univ. Chem. Technol. Metall. 2006, 41, 377-390.

49. Lehman, J.H.; Terrones, M.; Mansfield, E.; Hurst, K.E.; Meunier, V. Evaluating the characteristics of multiwall carbon nanotubes. Carbon 2011, 49, 2581-2602. [CrossRef]

50. Sato-Berrú, R.Y.; Basiuk, E.V.; Saniger, J.M. Application of principal component analysis to discriminate the Raman spectra of functionalized multi-walled carbon nanotubes. J. Raman Spectrosc. 2006, 37, 1302-1306. [CrossRef]

51. Zhao, X.; Ando, Y.; Qin, L.-C.; Kataura, H.; Maniwa, Y.; Saito, R. Multiple splitting of G-band modes from individual multi-walled carbon nanotubes. Appl. Phys. Lett. 2002, 81, 2550-2552. [CrossRef]

52. Dresselhaus, M.S.; Eklund, P.C. Phonons in carbon nanotubes. Adv. Phys. 2000, 49, 705-814. [CrossRef]

53. DiLeo, R.A.; Landi, B.J.; Raffaelle, R.P. Purity assessment of multi-walled carbon nanotubes by Raman spectroscopy. J. Appl. Phys. 2007, 101, 064307. [CrossRef]

54. Pimenta, M.A.; Dresselhaus, G.; Dresselhaus, M.S.; Cançado, L.G.; Jorio, A.; Saito, R. Studying disorder in graphite-based systems by Raman spectroscopy. Phys. Chem. Chem. Phys. 2007, 9, 1276-1291. [CrossRef] [PubMed]

55. Silva, W.M.; Ribeiro, H.; Seara, L.M.; Calado, H.D.R.; Ferlauto, A.S.; Paniago, R.M.; Leite, C.F.; Silva, G.G. Surface Properties of Oxidized and Aminated Multi-Walled Carbon Nanotubes. J. Braz. Chem. Soc. 2012, 23, 1078-1086. [CrossRef]

56. Alemán, B.; Vila, M.; Vilatela, J.J. Surface Chemistry Analysis of Carbon Nanotube Fibers by X-Ray Photoelectron Spectroscopy. Phys. Status Solidi A 2018, 215, 1800187. [CrossRef]

57. Behler, K.; Osswald, S.; Ye, H.; Dimovski, S.; Gogotsi, Y. Effect of thermal treatment on the structure of multi-walled carbon nanotubes. J. Nanoparticle Res. 2006, 8, 615-625. [CrossRef]

58. Susi, T.; Pichler, T.; Ayala, P. X-ray photoelectron spectroscopy of graphitic carbon nanomaterials doped with heteroatoms. Beilstein J. Nanotechnol. 2015, 6, 177-192. [CrossRef]

59. Nesov, S.N.; Korusenko, P.M.; Bolotov, V.V.; Povoroznyuka, S.N.; Smirnov, D.A. Electronic Structure of Nitrogen-containing Carbon Nanotubes Irradiated with Argon Ions: XPS and XANES Studies. Phys. Solid State A 2017, 59, 2030-2035. [CrossRef]

60. Chuang, C.-H.; Ray, S.C.; Mazumder, D.; Sharma, S.; Ganguly, A.; Papakonstantinou, P.; Chio, J.-W.; Tsai, H.M.; Shiu, H.-W.; Chen, C.-H.; et al. Chemical Modification of Graphene Oxide by Nitrogenation: An X-ray Absorption and Emission Spectroscopy Study. Sci. Rep. 2017, 7, 42235. [CrossRef]

61. Gautam, J.; Thanh, T.D.; Maiti, M.; Kim, N.H.; Lee, J.H. Highly efficient electrocatalyst of N-doped graphene-encapsulated cobalt-iron carbides towards oxygen reduction reaction. Carbon Vol. 2018, 137, 358-367. [CrossRef]

62. Rani, K.K.; Karuppiah, C.; Wang, S.F.; Alaswad, S.O.; Sireesha, P.; Devasenathipathy, R.; Jose, R.; Yang, C.-C. Direct pyrolysis and ultrasound assisted preparation of $\mathrm{N}, \mathrm{S}$ co-doped graphene $/ \mathrm{Fe}_{3} \mathrm{C}$ nanocomposite as an efficient electrocatalyst for oxygen reduction and oxygen evolution reactions. Ultrason. Sonochem. 2020, 66, 105111. [CrossRef]

63. Doniach, S.; Sunjic, M. Many-electron singularity in X-ray photoemission and X-ray line spectra from metals. J. Phys. C Solid State Phys. 1970, 3, 285. [CrossRef]

64. Guo, L.; Sun, J.; Ji, X.; Wei, J.; Wen, Z.; Yao, R.; Xu, H.; Ge, Q. Directly converting carbon dioxide to linear $\alpha$-olefins on bio-promoted catalysts. Commun. Chem. 2018, 1, 11. [CrossRef]

65. Grosvenor, A.P.; Kobe, B.A.; Biesinger, M.C.; McIntyre, N.S. Investigation of multiplet splitting of Fe 2p XPS spectra and bonding in iron compounds. Surf. Interface Anal. 2004, 36, 1564-1574. [CrossRef]

66. Biesinger, M.C.; Payne, B.P.; Grosvenor, A.P.; Laua, L.W.M.; Gerson, A.R.; Smart, R.S.C. Resolving surface chemical states in XPS analysis of first row transition metals, oxides and hydroxides: Cr, Mn, Fe, Co and Ni. Appl. Surf. Sci. 2011, 257, 2717-2730. [CrossRef] 
67. Wood, I.G.; Vocadlo, L.; Knight, K.S.; Dobson, D.P.; Marshall, W.G.; Price, G.D.J.; Brodholt, J. Thermal expansion and crystal structure of cementite, Fe3C, between 4 and $600 \mathrm{~K}$ determined by time-of-flight neutron powder diffraction. J. Appl. Crystallogr. 2004, 37, 82-90. [CrossRef]

68. Lee, G.H.; Kim, S.H.; Choi, B.J.; Huh, S.H.; Chang, Y.; Kim, B.; Park, J.; Oh, S.J. Magnetic properties of needle-like $\alpha$-FeOOH and $\gamma$-FeOOH nanoparticles. J. Korean Phys. Soc. 2004, 45, 1019-1024.

69. Valezi, D.F.; Piccinato, M.T.; Sarvezuk, P.W.C.; Ivashita, F.F.; Paesano, A., Jr.; Varalda, J.; Moscac, D.H.; Urbano, A.; Guedes, C.L.B.; Di Mauro, E. Goethite $(\alpha-\mathrm{FeOOH})$ magnetic transition by ESR, Magnetometry and Mössbauer. Mater. Chem. Phys. 2016, 173, 179-185. [CrossRef]

70. Boi, F.S.; Yuzhong Hua, Y.; Wen, J. New insights on the dynamics of the $\gamma$-Fe $/ \alpha$-Fe phase-transition inside iron-filled carbon nanotubes. RSC Adv. 2017, 7, 25025. [CrossRef]

71. Lipert, K.; Ritschel, M.; Leonhardt, A.; Krupskaya, Y.; Buchner, B.; Klingeler, R. Magnetic properties of carbon nanotubes with and without catalyst. J. Phys. Conf. Ser. 2010, 200, 072061. [CrossRef]

72. Gangwar, A.; Varghese, S.S.; Meena, S.S.; Prajapat, C.L.; Gupta, N.; Prasad, N.K. $\mathrm{Fe}_{3} \mathrm{C}$ nanoparticles for magnetic hyperthermia application. J. Magn. Magn. Mater. 2019, 481, 251-256. [CrossRef] 